\title{
Unemployment resistance across EU regions: the role of technological and human capital
}

\author{
Riccardo Cappelli ${ }^{1}$ (D) Fabio Montobbio ${ }^{2,3,4} \cdot$ Andrea Morrison $^{5,6}$
}

Published online: 15 July 2020

(C) The Author(s) 2020

\begin{abstract}
We investigate the unemployment impact of the 2008 crisis to study the relationship between economic and technological resilience in 248 European Union regions. For economic resilience we measure the difference between the level of unemployment rate before crisis and the level of unemployment rate at its peak after the crisis - i.e. the unemployment resistance. Using European Patent Office patents, we look at all technological crises in each region since 1978 and build a variable of technological resilience measuring the historical ability of a region to maintain its level of knowledge creation in the face of adverse shocks - i.e. the technological resistance. We find that technological resistance is a good predictor of unemployment resistance. In particular, our results show that (1) important interaction effects exist between technological resistance and human capital, (2) technological resistance and the level of human capital are less effective in protecting female and elder adult workers during an economic crisis and (3) important country level effects are present.
\end{abstract}

Keywords Economic resilience - Technological resilience · Unemployment - Recession · Human capital

JEL classification $033 \cdot \mathrm{R} 11 \cdot \mathrm{J} 64 \cdot \mathrm{J} 24 \cdot \mathrm{E} 24 \cdot \mathrm{G} 01$

\section{Introduction}

In May 2008 the unemployment rate for the EU-27 was at its minimum level. Between May 2008 and January 2013, it rose from $6.8 \%$ to 10.9\%. After reaching its maximum

\author{
Riccardo Cappelli \\ riccardo.cappelli@univpm.it \\ Fabio Montobbio \\ fabio.montobbio@unicatt.it \\ Andrea Morrison \\ a.morrison@uu.nl; andrea.morrison@unibocconi.it
}

Extended author information available on the last page of the article 
value it declined back to $7.1 \%$ in January 2018. The crisis and the recovery periods were also evident at the regional level and have affected the EU regions very differently over the last ten years. The economic downturn has dramatically hit some regional labor markets. The unemployment rate increased substantially not only in several Spanish and Greek regions, but also in many eastern regions of Bulgaria as well as in Baltic countries. Also, more innovative and advanced regions in Denmark, Northern Italy and the United Kingdom experienced a strong increase in their unemployment rates. In contrast, some regions in Germany, France and Belgium have continuously improved their economic conditions and local labor markets. All in all, the impact of the crisis was very heterogeneous across EU regions (Sensier et al. 2016).

The post crisis increase in the unemployment rate is often coupled with rising inequality, heterogeneous gender effects and deteriorating working conditions for young people (Verick 2009; Périvier 2014). Why is it that some regions have been able to recover quickly, some have failed to maintain their historical rates and others are lagging behind? Why are some regions more resilient than others in limiting the intensity of an economic shock and being able to invest and catch new economic opportunities? To what extent have crisis and recovery had a different impact on the different components of the labor force at the regional level?

Evolutionary economic geographers and economists have focused on the capacity of regions to react to economic crisis, reshaping their economic structures and redesigning their institutional settings to enter a new growth path. This capacity is called regional resilience. There is a large amount of literature on this issue and it is possible to look at the concept of regional resilience from different perspectives (Boschma 2015; Bristow 2010; Bristow and Healy 2014; Crescenzi et al. 2016; Diodato and Weterings 2014; Fingelton et al. 2012; Martin 2012; Martin and Sunley 2015; Martin et al. 2015; Pendall et al. 2010).

This paper develops the literature on the resilience of regions by looking at the impact of the 2008 economic crisis on European regions and it does so in four distinct directions. First of all, we claim that economic resilience is strongly influenced by technological resilience. We argue that the relative capacity of a region to produce and create technological knowledge and to maintain it over time, in particular during periods of economic crisis, is a key determinant of economic resilience (Filippetti and Archibugi 2011). We measure the economic resilience with labor market variables, as is usually done in this literature (Diodato and Weterings 2014; Fingleton et al. 2012). We consider unemployment resistance as a key dimension of economic resilience and we extend and articulate the concept tackling the heterogeneity of resilience according to different categories of the labor force. Specifically, we consider age, gender and the duration of unemployment. In doing, so we aim at addressing the question of who is affected by the crisis (Martin and Sunley 2015), and therefore which categories of workers benefit in regions with high unemployment resistance. In addition, our point of departure is that the technological resilience of regions depends to a great extent upon their technological history; in particular, the ability of a region to absorb shocks and its speed of recovery depend upon the past ability to reorienting skills, resources and technologies. As a result, we measure technological resilience with the ability of the regions to absorb and react to technological crisis, i.e. technological resistance (Balland et al. 2015). Finally, within the context of rapidly changing economic environments, the human capital and the skilled labor force have to be considered a "key ingredient" 
to generate and accumulate knowledge to promote new recombination and applications (Crescenzi et al. 2016).

In this paper, we estimate a cross section of 248 EU regions to show the main elements that are associated with unemployment resistance after the 2008 crisis. Unemployment resistance is the difference between the level of unemployment rate before crisis and the level of unemployment rate at its peak after the crisis. So we measure "the initial impact of the shock on a region's economy" (Martin and Sunley 2015: 13). We build an indicator, using patent data, of technological resistance based on the historical ability of the regions to react to technological crisis (Balland et al. 2015) and, controlling for many possible confounding factors, show that technological resistance is an important factor associated with unemployment resistance. We show also that this effect is particularly strong when coupled with a high level of human capital; at the same time, human capital alone is not enough to guarantee low unemployment rates after the crisis. We show also that the role of technological resistance is particularly important for regions that have a relatively more solid initial economic conditions. Also, it has a larger impact on the male and young labor force and on longterm unemployment. Importantly, we observe very strong country fixed effects. For some weak regions and for females and elders, country effects are the most significant variables affecting unemployment resistance. This latter finding suggests that the literature on regional resilience should take into account the complex and diverse interactions with the institutions and policies at the country level.

The paper is organized as follows. First, Section 2 presents the theoretical background and the existing empirical evidence. Sections 3 discusses our theoretical arguments concerning the determinants of economic resilience. Section 4 introduces data and methods, which include the measures of economic, technological resilience and human capital and the econometric specification. Section 5 presents the results. Section 6 provides a conclusion and a discussion of our findings.

\section{Theoretical background and empirical literature}

Since the inception of the Great Recession, a proliferation of theoretical and empirical studies have investigated the causes and impact of the economic crisis, and the concept of resilience has been widely used in academic and policy debates to understand how countries and regions cope with economic shocks (Boschma 2015; Bristow 2010; Bristow and Healy 2014; Crescenzi et al. 2016; Diodato and Weterings 2014; Filippetti and Archibugi 2011; Fingelton et al. 2012; Martin 2012; Martin and Sunley 2015; Martin et al. 2015; Pendall et al. 2010). In the literature, at least three different notions of resilience have been put forward and popularized (Pendall et al. 2010; Simmie and Martin 2010; Martin 2014): an engineering interpretation, an ecological interpretation and a complex adaptive interpretation.

The engineering definition became popular in disaster studies and conceptualizes resilience in terms of bounce back to a pre-existing state. Such an interpretation assumes that economic systems are on their long-term equilibrium path, which is occasionally broken up by shocks. Along this line of reasoning, regions are resilient when the self-correcting market mechanisms allow them to rebound to their long-term equilibrium state (Martin 2014). 
An ecological interpretation focuses on the ability of a system to absorb a shock. Differently from the previous definition, it assumes that a resilient system is one that is able to shift rapidly towards a new state of equilibrium, though possibly less favorable than the pre-crisis state, or alternatively, one that can absorb a relatively large shock. Also in the ecological definition (in line with the engineering one), resilient regions are able to accommodate a shock, while quickly adapting (with limited changes) their economic structure, so that the core activities and specialization are unaltered.

Finally, the third definition focuses on the capacity of regions to adapt and evolve in response to the changing external conditions. In this view, a resilient region changes its functions and structure in order to reach its long-term growth path and, differently from the other ones, it focuses on the long-term adaptability of a region (Martin and Sunley 2015). So, a resilient a region is able to turn a crisis into an opportunity for changing the actual economic structure and develop new activities (Boschma 2015). This view resonates in the Schumpeter's idea that a resilient region takes advantage of the gales of creative-destruction generated by a crisis (Schumpeter 1942).

In fact, Martin and Sunley (2015) emphasize that resilience is a composite process that includes many elements: vulnerability, shocks, resistance, robustness and recoverability. This paper mainly focuses on resistance, i.e. on the initial impact of the shock on a region's economy. However, it is important to underline that regional resilience is the composite effect of different forces, encompassing its vulnerability and its ability to absorb shocks and recover in each specific regional context.

Early empirical studies have mainly focused on the short-term impact of the crisis. A seminal work by Fingleton et al. (2012) shows that the UK regions show large differences in their ability to recover from shocks. Studying crisis events for a long time period (1970-2010), they observe that a short-run negative response to an unemployment shock is on average rapidly followed by employment growth in the longer run. However, this is mainly driven by the positive response of a number of regions while others have reacted negatively. However, this study does not dig further in the causes of resilience.

Another stream of literature, mainly drawing on evolutionary theorizing, has focused on the structural factors that allow regions to resist shocks and move towards new growth paths. ${ }^{1}$ This approach, by building on the Schumpeterian idea that crises are inherent features of capitalism, assumes that economic systems, and, accordingly, their industrial structure, have to cope constantly with the upturns and downturns of business cycles (Martin et al. 2015). Empirical studies using an evolutionary approach investigate regional resilience using a variety of economic phenomena besides standard performance indicators of an economy (e.g. GDP, unemployment), such as firm birth (Huggins and Thompson 2015); patenting dynamics (Balland et al. 2015), or the dynamics of specific industries (Doussard and Schrock 2015). These empirical analyses have generated rich empirical evidence on specific economic context (e.g. sectors, countries); however, they don't provide a comparative perspective, in particular on European regions.

Only a few empirical works have so far looked at the differential impact of shocks across European regions or countries. An early work of Groot et al.

\footnotetext{
${ }^{1}$ See special issues of the journal Cambridge Journal of Regions, Economy and Society (Volume 3, Issue 1, 2010; Volume 8: Issue 2, 2015).
} 
(2011) investigates the differential impact of the 2008 crises across European countries. These differences are related to a number of potential macro factors, which have possibly favored the transmission of the crisis. For example, they show that financial factors (e.g. government support to banks) played a major role, though their impact differed considerably across countries. In line with previous studies, they also found that trade openness represented an important transmission channel. Adding a wide range of institutional factors to the analysis, they show that their role differed greatly across EU countries.

A comparative analysis at the regional level can be found in Sensier et al. (2016). This work provides a new methodology to measure resilience in terms of resistance and recovery from a shock. By focusing on 289 NUTS2 regions of 31 European countries over the period 1990-2011, and looking at the 2008 crisis, they show that the time of entry into crisis differ across regions: for example, a few entered as early as 2006, while only in 2009 did most EU regions (i.e. 238) experience fully the effect of the economic crisis. Also, exit from the crisis shows lots of heterogeneity. In 2009, some regions already showed signs of recovery, while, by 2011, many did not show signal of recovery. So, the map of resilient regions is very diverse: one third proved to be resilient to the 2008 crisis, i.e. they did not experience a fall in employment, while another third was hit, but experienced a stop in employment fall by 2011. The remaining third part of regions was still suffering unemployment growth instead by then. The analysis, however, focuses on revealed resilience only, and, in the words of the authors, "It does not in and of itself tell us anything about resilience capacities or why different regions exhibited different resilience outcomes in relation to the economic shocks in question" (p. 148).

Finally, Crescenzi et al. (2016) adopt a cross regional perspective for the EU and estimate the regional determinants of resilience. They focus on the shortterm effects of the 2008 crisis on gross value added and unemployment, so it conceptualizes resilience as resistance to shocks. Explanatory factors include both national macro-economic determinants (e.g. FDI, institutions, public debt) as well as regional indicators of competitiveness (e.g. economic structure, human capital, innovation). Looking at the regional factors only, their analysis shows some interesting and perhaps unexpected findings. In particular, they show that human capital and innovation (captured by R\&D intensity) had opposite effects on regional performance during the crises. While human capital is positively associated with regional gross value added, the opposite happens for R\&D. According to the authors, these findings signal that "(...) regional resistance is not technology-driven innovation (captured by formalized R\&D investments), but rather a generally innovation- prone environment (captured by the abundance of human capital) that can facilitate process and organizational innovation (...)." (pag. 25). On the contrary, the same variables show reversed signs when the impact on employment is estimated, though both are statistically insignificant.

Similar to Crescenzi et al. (2016), our study provides comparative evidence of the impact of the 2008 crisis on EU regions. In the section below, we provide our framework of analysis and how we contribute to the extant empirical literature. 


\section{Economic and technological resilience in regions}

The impact of the 2008 crises was spatially uneven. Countries and regions had different abilities to cope with economic shocks and recover from them. A variety of factors have been put forward to explain why some regions might deal with shocks better than others (Martin 2012; Crescenzi et al. 2016; Groot et al. 2011). These determinants may include the region's economic structure, which refers to the degree of specialization or the relative share of manufacturing vs construction industry in a region; the institutional environment, for example, how flexible are the national or local labor markets or how effective is property rights enforcement; the degree of local and international interconnectedness as measured by trade flows or sectoral linkages (MacCann and Argiles 2015; Diodato and Weterings 2014) and, finally, human capital and innovation intensity (Martin 2012; Martin et al. 2015).

Our primary interest goes to this latter group of factors. We are interested in understanding the role of human capital and innovation for regional economic resilience. We refer here to a specific dimension of resilience that is called resistance, that is, the "the initial impact of the shock on a region's economy" (Martin and Sunley 2015: 13). As anticipated in the introduction, we argue that unemployment resistance represents a key dimension of economic resilience and measures the capacity of a region to absorb the level of unemployment generated by the crisis.

Theoretically, we adopt an evolutionary interpretation of technological resilience. The resistance to shocks depends primarily on the adaptability of a regional innovation system to external changing conditions. Following some recent literature (Balland et al. $2015),{ }^{2}$ we call this adaptive capacity technological resistance. Regions indeed differ not only in the size of their technological capital, but more importantly, in the capacity of adapting their technological assets (Kogler et al. 2013). Adaptability is in this case given by the regional innovation system's capacity of reorienting skills, resources and technologies (Boschma, 2015). We can expect that a regional innovation system with a strong long-term adaptive capacity of its technological structure (i.e. high technological resistance) would show also a higher capacity to cope with unemployment shocks (i.e. high unemployment resistance).

The link between technological and unemployment resistance can be studied looking at the role innovation during economic fluctuations. Some evidence suggests, for example, that in the 2008 economic crisis, countries relying on a strong innovation system accommodated better and responded more promptly to the economic shock (Filippetti and Archibugi 2011). Lucchese and Pianta (2011) have shown likewise that innovation activities support the economic growth of industries during economic upswings, and alleviate the negative impacts of economic downswings.

More generally, it is widely shared that economic systems (i.e. regional economies) endowed with strong and/or diversified knowledge assets have higher opportunities to recombine their knowledge and come up with novel products or processes (Boschma 2015). Under a crisis event, regions specialized in more dynamic sectors (e.g. hightech) will be less affected, since they operate in market segments or industries that are

\footnotetext{
${ }^{2}$ Balland et al. (2015) show that the technological resilience, i.e. the capacity to sustain the development of innovation activities facing an economic shock, of US cities is affected by factors suchs the composition of the internal knowledge base, the connectivity to external innovation systems and the institutional environment.
} 
overall more dynamic than average, and even if hit by the crisis, they will have greater chances than average region to reconfigure themselves and enter new promising markets/industries (Rocchetta and Mina, 2019).

Innovative regions can recover more quickly than non-innovative regions, in particular when high levels of human capital are present. Human capital, new skill formation and the presence of high innovative sectors can positively co-evolve generating a fast match between skills and jobs. Also at the regional level, there is some evidence showing that the presence of high-skilled workers allows local economic systems to adjust more promptly to the changes imposed by a shock (Crescenzi et al. 2016), although an opposite scenario can emerge in weak regions with strong human capital: in this case a skill matching problem will delay the recovery process.

Moreover, we can expect that innovative regions tend to attract more talented workers. In close analogy with sectors, it can be argued that high-skilled workers show higher adaptability, so they switch more easily from sectors in crisis to growing sectors. These workers can possibly upgrade faster their skill profiles and, in turn, adapt quicker to the new market requirements (Crescenzi et al. 2016; Cappelli et al. 2019). Therefore, a region endowed with a higher level of human capital might signal higher resilience to economic shocks.

It has been recently found, however, that innovation intensity, as compared to human capital, might react more slowly to exogenous shocks, since technological change (and related socio-institutional infrastructure) requires time to unfold and materialize, while, on the other hand, workers can acquire new skills and de-learn old ones rather quickly (Crescenzi et al. 2016). We will then explicitly address this paradox and check under which specific conditions it holds.

We will also focus on the heterogeneous effects that economic shocks have on the different components of the labor market, so addressing the question of who is affected by the crisis (Martin and Sunley 2015; Piva and Vivarelli 2018), that is, which categories of workers benefit the most in regions with high unemployment resistance. The crisis can indeed affect different components of the job market asymmetrically (Verick 2009). Our attention goes to three broad categories that characterize the labor force: age, gender and unemployment duration. Labor market outcomes of young workers are more sensitive to business cycle fluctuations than labor outcomes of older workers because young workers lack skills, work experience, job search abilities and the financial resources to find employment (ILO 2009; Verick 2009). On the other hand, aspects such as the gender segregation of labor markets, the role of women as cheap substitute workers and flexible labor supply might result in different responses (labor market outcomes) to economic cycle fluctuations for males and females (Rubery 1988). Finally, the variation in the average duration of unemployment is countercyclical (Sider 1985) and must be reflected in variation of the share of long-term unemployment. The heterogeneous effects of economic shocks push towards a consideration of the concept of resilience that takes into account the distributional aspects (Martin and Sunley 2015). In weak labor market conditions, it is difficult for anyone to find a new job, but factors such as human capital depreciation and the stigma associated with the lengthening of unemployment (Blanchard and Diamond 1994) reduce extremely the probability of finding a job for the long-term unemployed. Furthermore, for youth, the failure to find a first job or to keep it might permanently compromise their future employment prospects and earnings capacity (Scarpetta et al. 2010). 


\section{Methods, data and variables}

This paper constructs a set of variables for the regions of the European Union's 27 countries, relying on two databases. EUROSTAT's regional database provides the main economic and demographic variables used in the analysis (e.g. the unemployment rates for the period 2007-2016; the shares of population aged 25-64 with a tertiary education in $2006^{3}$; the population in 2006; the shares of employees in agriculture, manufacturing, construction and services sectors in 2006). In addition, the ICRIOSPATSTAT database on EPO patent applications for the period 1978-2010 (see Coffano and Tarasconi 2014) is used to construct the variables related to the technological activities of regions (e.g. stock of patents in 2006, the Herfindhal index of technological diversification in 2006 and the variable used to measure the technological resistance of regions explained below). ${ }^{4}$ The initial database contains 270 NUTS2 regions (EUROSTAT 2011) of 27 countries. However, twenty-two regions are excluded from the analysis because of data constraints. ${ }^{5}$ The final sample contains 248 regions in 26 countries (i.e. the EU27 countries, excluding Slovenia).

\subsection{Unemployment resistance}

Resistance is a dimension of resilience and represents the initial impact of a shock on a region's economy (Martin and Sunley 2015: 13). We study unemployment resistance at the regional level and we measure it with the difference between the level of unemployment rate before crisis and the level of unemployment rate at its peak after the crisis. By excluding the decline of the unemployment rates after its peak generated by the shock, we can safely assume that our measure of unemployment resistance does not capture also the recovery phase. In line with the existing literature (e.g. Crescenzi et al. 2016; Martin et al. 2015), we use the year 2008 as the starting year of the recession period. So, observing the unemployment rate of region $i$ in the period 2008-2016, the unemployment resistance of region $i$ (UNEMPres U $_{i, 2008-2016)}$ is calculated in the following way:

$$
\text { UNEMPres }_{i, 2008-2016}=-\log \left(\max U N E M P_{i, 2008-2016} / \text { UNEMP }_{i, 2007}\right)
$$

where, for a given region $i, \max U N E M P_{i, 2008-2016}$ is the maximum total unemployment rate observed during the period 2008-2016 and $U N E M P_{i, 2007}$ is the total unemployment rate in 2007. Equation [1] can also be expressed as UNEMPres ${ }_{i, 2008-}$ $2016=\log \left(U N E M P_{i, 2007}\right)-\log \left(\max U N E M P_{i, 2008-2016}\right)$, so unemployment resistance (UNEMPres ${ }_{i, 2008-2016)}$ is a negative function of the maximum

\footnotetext{
${ }^{3}$ Tertiary education is defined according to the International Standard Classification of Education (ISCED) levels 5, 6, 7 and 8 (short-cycle tertiary education, bachelor's or equivalent level, master's or equivalent level, doctoral or equivalent level).

${ }^{4}$ As is standard in the literature (see e.g. Jaffe and Trajtenberg 2002; Cappelli and Montobbio 2016), patents are attributed to regions using the inventors' addresses.

${ }^{5}$ Nine regions (ES63, ES64, FI20, FR83, FR91, SI01, SI02, UKI1 and UKI2) are discarded because of missing data on unemployment rates. For three regions (FR92, FR93 and FR94) there is no information about human capital. Finally, ten regions (DE13, DE60, DK01, EL22, EL41, ES51, FI19, ITH5, PT20 and SK02) are discarded because no technological recession phases are observed for these regions (see below). As a robustness check, additional estimates are performed, including the latter ten regions.
} 
unemployment rate observed during the post-crisis period (2008-2016) (see also footnote 8 in Section 4.4).

Figure 1 shows the $\log$ of total unemployment rate in $2007\left(\log \left(U N E M P_{i, 2007}\right)\right)$ (panel a) and the unemployment resistance during crisis for the European regions (UNEMPres $i, 2008-2016$ ) (panel b). Figure 1 (panel b) shows that the most performing regions (i.e. regions with the lowest increase in the unemployment rates) are located mainly in Germany and Poland, while the most severely hit regions are located mainly in Greece, Ireland, Italy, Spain and the Baltic states. All the other regions are in between these two groups of regions with strong opposite performance. Overall, then emerges, a strong country effect, which will have to be accounted for in empirical analysis.

Data reported in Fig. 1 (panel b) suggest that the regional performance during the crisis is affected by the initial level of unemployment. Some regions had a high (low) initial level of unemployment combined with a relatively good (low) performance during the crisis period. Overall, European regions show a high degree of heterogeneity. For example, some northern Italian region such as Piedmont and Lombardy had a low unemployment rate in 2007 and, at the same time, were among the most hit by the 2008 crisis. On the other side, quite a few regions in Poland showed high rates of unemployment in 2007, but also high unemployment resistance.

\subsection{Technological resistance}

As underlined above, we argue that it is not the intensity of technological capital per se that influences the unemployment resistance of regions. We argue that, thanks to some characteristics of technological capital, regions are able to react facing adverse conditions. Then, we build an index that measures the capacity of regions to have limited downturns in the production of innovations during technological crises. We use a modified version of the methodology adopted by Balland et al. (2015). This procedure uses the time series of yearly regional patent data to capture the dynamics in the regions' production of inventions. These time series may be viewed as a continuum of local maxima (peak) and local minima (trough) that divide the regional patent series into periods of technological growth (from a trough point to a peak point) and technological crisis (from a peak point to a trough point). Focusing on the technological

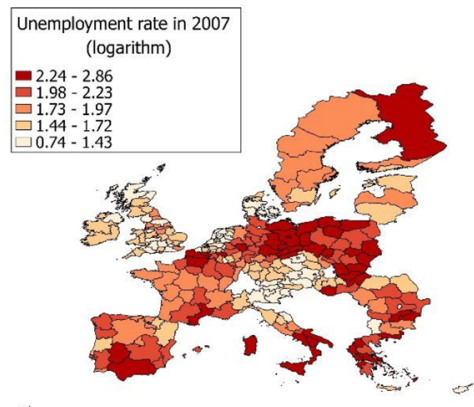

a) logarithm of regional unemployment rate in 2007

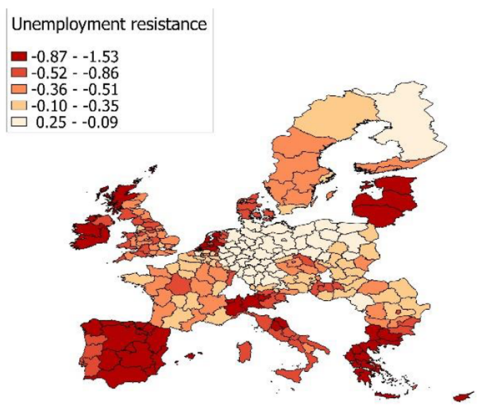

b) regional unemployment resistance for the period 2008-2016

Fig. 1 Unemployment rate in 2007 and unemployment resistance for the period 2008-2016 for the 248 NUTS2 European regions: panel a) logarithm of regional unemployment rate in 2007); and panel b) regional unemployment resistance for the period 2008-2016 


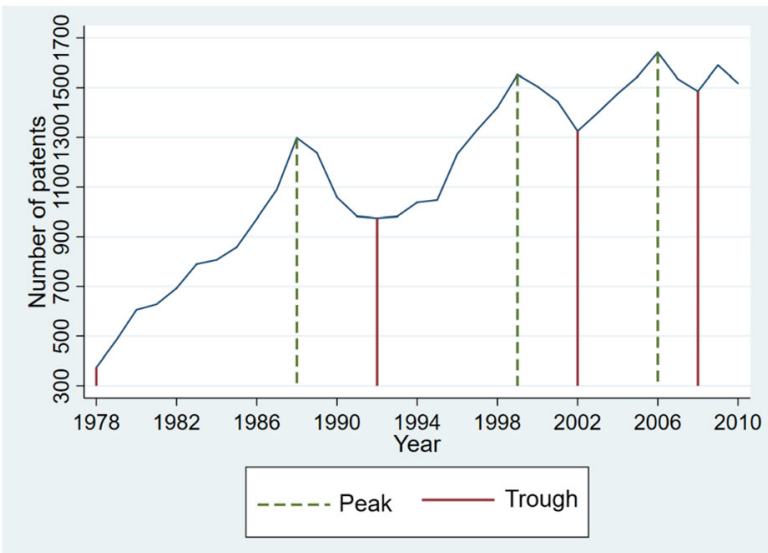

Fig. 2 Peak, trough and technological cycles for Dusseldorf (NUTS2: DEA1)

crisis periods, the reduction in the number of produced patents from the peak to the trough points is used to measure the intensity of the technological crisis and, thus, to capture the degree of resistance to it.

More formally, in line with Balland et al. (2015), we use an adapted version of the algorithm developed by Harding and Pagan (2002) and apply it to yearly regional patent data for the period 1978-2010. This methodology identifies the turning points, (i.e. the peak and trough points in the time series) and specifies a minimum duration of the phases (period between a peak and a trough or vice versa) and cycles (period between two peaks or troughs). In particular, we require that the duration of phases and cycles is, respectively, two and five years at least (see Balland et al. 2015). Specifically, let $P A T_{i, t}$ to be the number of patents of region $i$ at time $t$, a peak $\left(P A T_{i, t}^{\text {peak }}\right)$ occurs at time $t$ if $\left(P A T_{i, t-2}\right.$ ,$\left.P A T_{i, t-1}\right)<P A T_{i, t}^{\text {peak }}>\left(P A T_{i, t+1}, P A T_{i, t+2}\right)$, while a trough $\left(P A T_{i, t}^{\text {trough }}\right)$ occurs at time $t$ if $\left(P A T_{i, t-2}, P A T_{i, t-1}\right)>P A T_{i, t}^{\text {trough }}<\left(P A T_{i, t+1}, P A T_{i, t+2}\right)$. As an example, Fig. 2 shows the peak and trough points identified for the German region Dusseldorf.

Once the turning points are identified for each technological recession phase ending before the year $2006,{ }^{6}$ the number of patents at the peak (i.e. the last period before the starting of a technological recession phase) and the number of patents at the trough (i.e. the ending period of a technological recession phase) are used to compute the peak-trough ratio $\left(P T R_{i, t}\right)$ in the following way: $P T R_{i, t}=\left(P A T_{i, t}^{\text {peak }}-P A T_{i, t}^{\text {trough }} / P A T_{i, t}^{\text {peak }}\right) * 100$. The peak-trough ratio ranges between 0 (if the region produces the same number of patents at the peak and the trough point) and 100 (if the region does not develop any patents at the trough). The peak-trough ratios are used by Balland et al. (2015) to measure the intensity of technological crises. In order to measure technological resistance (TECHres T $_{i, 1978-2006}$ ), we take the opposite of the peak-trough ratio: TECHres TE, 1978-2006 $=-$ PTR $_{i, t}$. Higher

\footnotetext{
$\overline{6}$ This paper allows technological recession phases to start in 1978 because of data truncation before 1978. For the last period considered, i.e. the year 2006, only recession phases ending before 2006 are considered to avoid overlapping periods with those used to calculate the unemployment performance over the recent economic crisis. This is done to mitigate the endogeneity bias. Additional robustness checks performed to ensure the validity of the main results do not rely on the way the technological resilience measure is computed.
} 
values of TECHres ${ }_{i, 2006}$ correspond to higher levels of technological resistance to a technological crisis. Since regions might see two or more technological recession phases during the period 1978-2006, the empirical analysis uses the mean value of the opposite values of the regional peak-trough ratio observed for the period 1978-2006.

Figure 3 shows the technological resistance level (TECHres, 1978-2006) for the European regions. Regions with the highest level of technological resistance are mainly located in the Central-Northern European regions. Moreover, the map shows that in Germany, Netherlands, Spain, Portugal and the Eastern European countries, regions are rather homogeneous, while other countries such as Italy, Sweden and the United Kingdom show a higher intra-national regional variance.

Table 1 shows the mean value of technological and unemployment resistance for five group of regions ranked according to their levels of technological resistance. It suggests that, on average, higher values of technological resistance are associated with higher values of unemployment resistance.

\subsection{Human capital}

Finally, we look at the performance of regions distinguishing between regions with low and high human capital before the 2008 crisis. In particular, we measure human capital in 2006 (HUMANCap $_{i, 2006}$ ) as the percentage of people aged 25-64 with a tertiary education. The median value of HUMANcap ${ }_{i, 2006}$ is used to discriminate between the two groups of regions. The percentage mean value of unemployment resistance is $-43.3 \%$ for regions with low human capital and $-52.9 \%$ for regions with high human capital. ${ }^{7}$ It follows that, on average, regions with high level of human capital are more affected by the crisis than regions with low level of human capital. In addition, for each group, using the median value of TECHres T, $1978-2006_{\text {we distinguish between regions }}$ with low and high level of technological resistance. Table 2 shows the mean value of unemployment resistance (UNEMPres ${ }_{i, 2008-2016)}$ for these four groups. It clearly emerges that, on average, regions with a high level of technological resistance perform better irrespectively of the level of human capital. On the other side, the difference in performance is greater for the group of regions with high human capital. In sum Table 2 suggests that important interaction effects exist between technological resistance and human capital. In fact, technological resistance improves significantly the unemployment resistance in particular in those regions with high levels of human capital.

\subsection{Methodology}

We model regional economic resilience using unemployment resistance. Our two main variables of interests are technological resistance $\left(\right.$ TECHres $\left._{i, 1978-2006}\right)$ and human capital $\left(\right.$ HUMANCap $_{i, 2006}$ ). As a result, UNEMPres $_{i, 2008-2016}$ is modeled using the following equation ${ }^{8}$ :

\footnotetext{
${ }^{7}$ The result of a t-test show that the two mean values are significantly different at the $1 \%$ level.

${ }^{8}$ Equation [2] can be rewritten as: [2] $-\log \left(\max U N E M P_{i, 2008-2016} / U N E M P_{i, 2007}\right)=\alpha+\pi \log \left(U N E M P_{i}\right.$, $2007)+x^{\prime} \beta+\varepsilon_{i}$, where $x^{\prime}$ is the vector of independent variables. An analogous specification would be: $[2 a] \log \left(\max U N E M P_{i, 2008-2016}\right)=-\alpha+(1-\pi) * \log \left(U N E M P_{i, 2007}\right)-x^{\prime} \beta-\varepsilon_{i}$. So, in fact, we are estimating the determinants of the maximum unemployment rate between 2008 and 2016, controlling for the level of unemployment in 2007. The post-crisis recovery period is not included.
} 


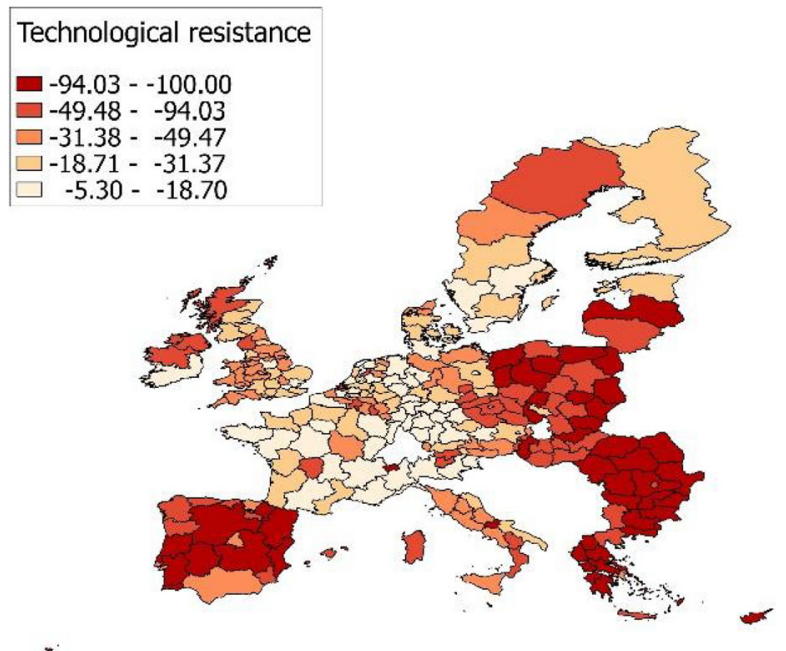

Fig. 3 Technological resistance index for the 248 NUTS2 European regions for the period 1978-2006

$$
\begin{aligned}
& \text { UNEMPres }_{i, 2008-2016} \\
&=\alpha+\pi \log \left(\text { UNEMP }_{i, 2007}\right)+\beta \text { TECHres }_{i, 1978-2006}+\varphi \text { HUMANcap }_{i, 2006} \\
&+\Omega \text { RECyears }_{i, 1978-2006}+\pi \text { PATp }_{i, 2006}+\rho \text { HERFtech }_{i, 2006}+\varphi \text { GDPpc }_{i, 2006} \\
&+\gamma \log \left(\text { POP }_{i, 2006}\right)+\delta \text { CAPITAL }_{i, 2006}+\eta \text { AGRIC }_{i, 2006}+\text { MANUF }_{i, 2006} \\
&+\operatorname{CONSTR}_{i, 2006}+\theta^{\prime} C+\varepsilon_{i}
\end{aligned}
$$

Equation [2] represents the main model. Additional regressions are performed including the interaction between technological resistance and human capital, as suggested by the descriptive evidence in Table 2. We control for a number of factors that affect UNEMPres $_{i, 2008-2016}$ and could be correlated with TECHres, $1978-2006$ and HUMANcap ${ }_{i, 2006}$.

In particular, we consider a set of regional characteristics possibly correlated with the regional performance during the crisis period. We include RECyears $_{i, 1978-2006}$ : the sum of the number of years of technological recession in region $i$ during the period 1978-2016. In the case of multiple recession phases, all of them have been considered. This variable controls for the overall intensity of the technological crises at the regional level and, consequently, for the vulnerability of the regional technological system (Balland et al. 2015; Martin and Sunley 2015). The patent stock per capita in 2006 (PATpc $\left.c_{i, 2006}\right)$ controls for the size of the region's technological capital. $P A T p c_{i, 2006}$ is computed as the ratio between the sum of patents for the years 1978 to 2006 and the population in 2006. The specialization of the region's technological capital could also play an important role. So, we calculated the Herfindahl index in 2006 for each region using the shares of patents in different technological fields $\left(\right.$ HERFtech $\left._{i, 2006}\right)$. We used the IPC (international patent classification) classification at the four-digit level. The GDP per capita in 2006 
Table 1 Mean value of technological and unemployment resistance for five groups of regions ranked according to their levels of technological resistance

\begin{tabular}{lll}
\hline Technological resistance & & Unemployment resistance \\
\hline Ranking position & Mean & Mean \\
\hline From 1 to 50 & -13.52 & -0.29 \\
From 51 to 100 & -24.11 & -0.42 \\
From 101 to 150 & -40.44 & -0.47 \\
From 151 to 200 & -74.33 & -0.58 \\
From 201 to 248 & -99.82 & -0.66 \\
Total & -50.05 & -0.49 \\
\hline
\end{tabular}

Notes: each of the 248 European NUTS2 regions considered by our analysis is included in one of the five groups of regions based on its ranking position in terms of technological resistance level

$\left(G D P p c_{i, 2006}\right)$ is included to control for the overall level of economic development. The logarithm of population in $2006\left(P O P_{i, 2006}\right)$ controls for the size of the region. A dummy for capital regions in $2006\left(C A P I T A L_{i, 2006}\right)$ is also included: capital regions tend to outperform other regions thanks to several factors such as the higher concentration of research institutes and high value-added activities (Hoekman et al. 2009; Dijkstra et al. 2015). We also control for the shares of employment in agriculture $\left(A G R I C_{i, 2006}\right)$, manufacturing $\left(M A N U F_{i, 2006}\right)$ and construction $\left(C O N S T R_{i, 2006}\right)$ (services sector is used as a reference category) in 2006. Finally, a set of country dummies $(C)$ are included to control for all country level unobserved characteristics.

All estimates are performed using OLS regressions. To facilitate the comparison of the regression coefficients, the continuous independent variables are standardized, dividing them by two times the sample standard deviation, while the dichotomous independent variables are centered around their sample mean (i.e., demeaned) (Gelman 2008). The adopted linear rescaling changes the coefficient values of the independent variables, but it does not change the associated t-statistics and $p$-values.

Table 2 Mean value of unemployment resistance by group of regions with low or high level of human capital and technological resistance

\begin{tabular}{llll}
\hline & & \multicolumn{2}{l}{ Technological resistance } \\
\cline { 3 - 3 } & & Low & High \\
\hline \multirow{2}{*}{ Human capital } & Low & -0.50 & -0.31 \\
& High & -0.75 & -0.41 \\
\hline
\end{tabular}

Notes: each of the 248 European NUTS2 regions considered by our analysis is included in one of the four group of regions based on its level of human capital and technological resistance; Low and High means, respectively, lower and upper median value in terms of human capital (under the rows) and technological resistance (under the columns); the result of the mean comparison t-test (not show here for the sake of clarity) performed for the two groups of regions with Low human capital and for the two groups with High human capital is significant at $1 \%$ level 
To analyze whether the effects of technological resistance and human capital on unemployment resistance differ by gender, age (i.e. young: age 15-24 vs. elders: age > 24) and unemployment duration (i.e. long-term unemployed: unemployment condition $>12$ months), for each group of unemployment, we compute the corresponding unemployment resistance (i.e. the dependent variable) using equation [1]. All the other independent variables are kept unchanged.

\section{Results}

\subsection{Results for total unemployment}

Table 3 shows the descriptive statistics of the unstandardized regression variables and Table 4 shows the results of the OLS estimates for total unemployment.

In Table 4, models in columns 1a, $2 \mathrm{a}$ and $3 \mathrm{a}$ show the baseline specifications, while models $1 \mathrm{~b}, 2 \mathrm{~b}$ and $3 \mathrm{~b}$ show the specifications with the interaction effect between technological resistance and human capital. Models $1 \mathrm{a}$ and $1 \mathrm{~b}$ show the results controlling only for the unemployment rate in 2007. Models $2 \mathrm{a}$ and $2 \mathrm{~b}$ extend the basic models by adding all the other control variables with the exception of the country dummies. Models $3 \mathrm{a}$ and $3 \mathrm{~b}$ show the results when the country dummies are included. ${ }^{9}$

In all models we find a significant and positive effect of technological resistance (TECHres $i, 1978-2006)$. This means that technological resistant regions experienced a lower increase in the unemployment rates after the 2008 crisis and therefore display a higher level of unemployment resistance. This result suggests that region i's unemployment resistance during the recent crisis is associated with its historical capacity to remain innovative in front of adverse shocks. We have assumed that this capacity reflects the adaptability of a regional innovation system to external changing conditions. This takes place thanks to the ability of regions to reconfigure the technological structure by reorienting skills and resources in novel ways (Balland et al. 2015). Our results are coherent with Archibugi et al. (2013), who found that companies pursuing an explorative strategy towards new products and market development are those with better innovation performance during the recent crisis.

The coefficient of the human capital variable $\left(H_{U M A N c a p}, 2006\right)$ is negative and significant in specifications $1 \mathrm{a}, 1 \mathrm{~b}, 2 \mathrm{a}$ and $2 \mathrm{~b}$. However, when country dummies are included in the model ( $3 a$ and $3 b$ ), the coefficient of human capital is not statistically significant, suggesting that human capital alone is not enough to ensure unemployment resistance. A positive effect of human capital on unemployment resistance appears only when this variable is interacted with the variable of technological resistance (see Model 3b). Overall, these results are in line with some recent studies (Ramos et al. 2019; Cadil et al. 2014) that stress that higher human capital does not always guarantee low unemployment over economic cycles.

The positive and significant coefficient of the interaction term between technological resilience and human capital (TECHres ${ }_{i, 1978-2006} *$ HUMANCap $_{i, 2006}$ ) suggests that

\footnotetext{
${ }^{9}$ For each model, a variance inflation factor test is performed. The results range from 1.08 of the basic model (Model 1a) to 3.10 of the most extended model (Model 3b). Therefore, we conclude that multicollinearity is not a concern. 
Table 3 Descriptive statistics of the unstandardized variables $(N=248)$

\begin{tabular}{lllll}
\hline Variable & Mean & SD & Min & Max \\
\hline UNEMPres $_{\mathrm{i}, 2008-2016}$ & -0.481 & 0.406 & -1.528 & 0.254 \\
$\log \left(\right.$ UNEMP $\left._{\mathrm{i}, 2007}\right)$ & 1.841 & 0.440 & 0.742 & 2.862 \\
TECHres $_{\mathrm{i}, 1978-2006}$ & -50.046 & 32.877 & -100 & -5.304 \\
HUMANcap $_{\mathrm{i}, 2006}$ & 22.555 & 7.915 & 8.000 & 45.500 \\
RECyears $_{\mathrm{i}, 1978-2006}$ & 6.387 & 3.874 & 2 & 19 \\
PATpc $_{\mathrm{i}, 2006}$ & 1.704 & 2.109 & 0.002 & 11.276 \\
HERFtech $_{\mathrm{i}, 2006}$ & 0.071 & 0.106 & 0.008 & 0.611 \\
GDPpc $_{\mathrm{i}, 2006}$ & 0.024 & 0.009 & 0.006 & 0.064 \\
AGRIC $_{\mathrm{i}, 2006}$ & 0.059 & 0.066 & 0.003 & 0.439 \\
MANUF $_{\mathrm{i}, 2006}$ & 0.194 & 0.069 & 0.058 & 0.388 \\
CONSTR $_{\mathrm{i}, 2006}$ & 0.085 & 0.024 & 0.039 & 0.170 \\
${\text { log }\left(\text { POP }_{\mathrm{i}, 2006}\right)}_{\text {CAPITAL }_{\mathrm{i}, 2006}}^{7.267}$ & 0.736 & 4.820 & 9.353 \\
\hline
\end{tabular}

Notes: country dummies are not included for the sake of clarity

human capital helps regions cope with unemployment shocks if it is supported by an adequate technological long-term capacity to be resilient to shocks. Similarly, it suggests that the regional technological resistance is particularly effective at facing an economic downturn when the region has also a high level of human capital. ${ }^{10,11}$

Our results are robust to the inclusion of country dummies (see Models 3a and 3b) and their role is particularly important in the model, as shown by the increase of R-squared (from 0.62 up to 0.93 ). In addition, the estimated effect of technological resistance decreases from 0.24 to 0.13 (Models $2 \mathrm{~b}$ and 3b). Almost half of the effect of technological resistance is captured by country level variables. Therefore, an important portion of the technological resistance at the regional level is affected by the characteristics of the country. Institutional and policy factors at the country level clearly play a role in regional innovation systems

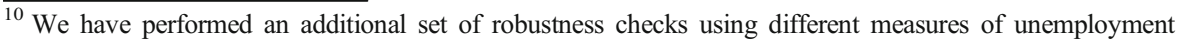
resistance. First, we have used in equation (1) the expected unemployment rate at the peak of the crisis, calculated using a compound growth rate for the pre-crisis period (Han and Goetz 2015). Second, we have also

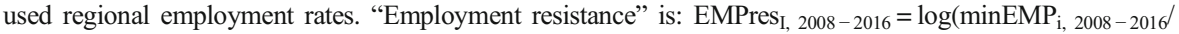
$\mathrm{EMP}_{\mathrm{i}, 2007}$ ), where minEMP $\mathrm{i}_{\mathrm{i} 2008-2016}$ is the minimum employment rate observed during the period 20082016 and $\mathrm{EMP}_{\mathrm{i}, 2007}$ is employment rate in 2007 of a given region $i$. Our results are robust to these different specifications.

${ }^{11}$ It is interesting to note that our results display some differences when we consider "GDP per capita resistance" instead of unemployment resistance. GDP per capita resistance is defined as in equation [1]: GDPres $i_{i, 2008-2016}=\log \left(\operatorname{minGDPpc}_{i, 2008-2016} / \mathrm{GDPpc}_{\mathrm{i}, 2007}\right)$, where $\operatorname{minGDPp}_{\mathrm{i}, 2008-2016}$ is the minimum GDP per capita observed during the period 2008-2016 and GDPpc $\mathrm{i}_{\mathrm{i}, 2007}$ is GDP per capita in 2007 of a given region $i$. We find that both technological resistance and the interaction term have, as expected, a positive effect on GDP per capita resistance. However, when all the European regions are considered together, in line with Crescenzi et al. (2016), we find that that only human capital exerts a statistically significant effect on GDP per capita resistance. In general, it seems that the long-term ability of regions to adapt to changing conditions is a less powerful predictor of the short-term changes in the regional GDP per capita. This is true, in particular, for less wealthy regions: see also below footnote 13 . Results are available from the authors upon request.
} 
Table 4 Determinants of regional unemployment resistance - OLS estimates

\begin{tabular}{|c|c|c|c|c|c|c|}
\hline VARIABLES & Model 1a & Model 1b & Model 2a & Model 2b & Model 3a & Model 3b \\
\hline $\log \left(\mathrm{UNEMP}_{\mathrm{i}, 2007}\right)$ & $\begin{array}{l}0.361 * * * \\
(0.044)\end{array}$ & $\begin{array}{l}0.357 * * * \\
(0.043)\end{array}$ & $\begin{array}{l}0.368 * * * \\
(0.039)\end{array}$ & $\begin{array}{l}0.372 * * * \\
(0.038)\end{array}$ & $\begin{array}{l}0.267 * * * \\
(0.026)\end{array}$ & $\begin{array}{l}0.258 * * * \\
(0.026)\end{array}$ \\
\hline TECHres $_{\mathrm{i}, 1978-2006}$ & $\begin{array}{l}0.419 * * * \\
(0.048)\end{array}$ & $\begin{array}{l}0.479 * * * \\
(0.048)\end{array}$ & $\begin{array}{l}0.212 * * * \\
(0.068)\end{array}$ & $\begin{array}{l}0.243 * * * \\
(0.066)\end{array}$ & $\begin{array}{l}0.107 * * * \\
(0.040)\end{array}$ & $\begin{array}{l}0.132 * * * \\
(0.040)\end{array}$ \\
\hline HUMANcap $_{i, 2006}$ & $\begin{array}{l}-0.166^{* * *} \\
(0.048)\end{array}$ & $\begin{array}{l}-0.172^{* * *} \\
(0.046)\end{array}$ & $\begin{array}{l}-0.092 * * \\
(0.046)\end{array}$ & $\begin{array}{l}-0.103^{* *} \\
(0.045)\end{array}$ & $\begin{array}{l}-0.027 \\
(0.037)\end{array}$ & $\begin{array}{l}-0.050 \\
(0.037)\end{array}$ \\
\hline $\begin{array}{r}\text { TECHres }_{i, 1978-2006} * \\
\text { HUMANcap }_{i, 2006}\end{array}$ & & $\begin{array}{l}0.440 * * * \\
(0.092)\end{array}$ & & $\begin{array}{l}0.304 * * * \\
(0.085)\end{array}$ & & $\begin{array}{l}0.158 * * * \\
(0.048)\end{array}$ \\
\hline RECyears $_{\mathrm{i}, 1978-2006}$ & & & $\begin{array}{l}0.064 \\
(0.041)\end{array}$ & $\begin{array}{l}0.066 \\
(0.040)\end{array}$ & $\begin{array}{l}0.019 \\
(0.021)\end{array}$ & $\begin{array}{l}0.023 \\
(0.021)\end{array}$ \\
\hline PATpc $_{i, 2006}$ & & & $\begin{array}{l}0.206^{* * *} \\
(0.053)\end{array}$ & $\begin{array}{l}0.173 * * * \\
(0.053)\end{array}$ & $\begin{array}{l}0.010 \\
(0.028)\end{array}$ & $\begin{array}{l}-0.014 \\
(0.029)\end{array}$ \\
\hline HERFtech $_{\mathrm{i}, 2006}$ & & & $\begin{array}{l}-0.002 \\
(0.049)\end{array}$ & $\begin{array}{l}-0.058 \\
(0.051)\end{array}$ & $\begin{array}{l}0.016 \\
(0.027)\end{array}$ & $\begin{array}{l}-0.010 \\
(0.028)\end{array}$ \\
\hline GDPpc $_{\mathrm{i}, 2006}$ & & & $\begin{array}{l}-0.133 * * \\
(0.063)\end{array}$ & $\begin{array}{l}-0.113 * \\
(0.061)\end{array}$ & $\begin{array}{l}0.131 \text { *** } \\
(0.043)\end{array}$ & $\begin{array}{l}0.128^{* * *} \\
(0.042)\end{array}$ \\
\hline AGRIC $_{i, 2006}$ & & & $\begin{array}{l}-0.087 \\
(0.053)\end{array}$ & $\begin{array}{l}-0.096 * \\
(0.052)\end{array}$ & $\begin{array}{l}0.033 \\
(0.032)\end{array}$ & $\begin{array}{l}0.026 \\
(0.032)\end{array}$ \\
\hline MANUF $_{i, 2006}$ & & & $\begin{array}{l}0.137 * * * \\
(0.047)\end{array}$ & $\begin{array}{l}0.155^{* * *} \\
(0.046)\end{array}$ & $\begin{array}{l}0.009 \\
(0.028)\end{array}$ & $\begin{array}{l}0.016 \\
(0.027)\end{array}$ \\
\hline CONSTR $_{\mathrm{i}, 2006}$ & & & $\begin{array}{l}-0.323^{* * *} \\
(0.046)\end{array}$ & $\begin{array}{l}-0.294 * * * \\
(0.046)\end{array}$ & $\begin{array}{l}-0.012 \\
(0.033)\end{array}$ & $\begin{array}{l}-0.013 \\
(0.032)\end{array}$ \\
\hline $\log \left(\mathrm{POP}_{\mathrm{i}, 2006}\right)$ & & & $\begin{array}{l}-0.087^{* *} \\
(0.044)\end{array}$ & $\begin{array}{l}-0.093 * * \\
(0.043)\end{array}$ & $\begin{array}{l}-0.011 \\
(0.026)\end{array}$ & $\begin{array}{l}-0.018 \\
(0.026)\end{array}$ \\
\hline CAPITAL $_{\mathrm{i}, 2006}$ & & & $\begin{array}{l}0.016 \\
(0.069)\end{array}$ & $\begin{array}{l}0.008 \\
(0.068)\end{array}$ & $\begin{array}{l}-0.109 * * \\
(0.048)\end{array}$ & $\begin{array}{l}-0.095 * * \\
(0.047)\end{array}$ \\
\hline Constant & $\begin{array}{l}-0.482 * * * \\
(0.022)\end{array}$ & $\begin{array}{l}-0.527 * * * \\
(0.022)\end{array}$ & $\begin{array}{l}-0.486^{* * *} \\
(0.018)\end{array}$ & $\begin{array}{l}-0.517 * * * \\
(0.020)\end{array}$ & $\begin{array}{l}-0.064 * * \\
(0.030)\end{array}$ & $\begin{array}{l}-0.065^{* *} \\
(0.030)\end{array}$ \\
\hline Country dummies & No & No & No & No & Yes & Yes \\
\hline Observations & 248 & 248 & 248 & 248 & 248 & 248 \\
\hline R-squared & 0.329 & 0.387 & 0.597 & 0.618 & 0.931 & 0.934 \\
\hline
\end{tabular}

Notes: Standard errors in parentheses; $* * * p<0.01, * * p<0.05, * p<0.1$

and affect local unemployment. Moreover, country dummies are almost always statistically significant. As shown in Table 8 in the appendix, unemployment resistance is particularly low for Estonia, Greece, Spain, Ireland, Lithuania, Latvia, Portugal and Italy, as compared to Germany, the reference category.

The estimation of Model $3 \mathrm{~b}$ shows that the log of the unemployment level at the initial period $\left(U N E M P_{i, 2007}\right)$ is statistically significant and has a positive sign. Regions with higher unemployment rates, ceteris paribus, show higher unemployment resistance. We also find a positive and significant effect of GDP per capita $\left(G D P p c_{i, 2006}\right)$. 
This means that, other things being equal, richer regions were less affected by the recent economic crisis, at least in terms of unemployment rates. In addition, there is a negative and significant effect of the dummy that identifies capital regions $\left(C A P I T A L_{i}\right.$, 2006). A possible explanation can be attributed to the volatile effects of agglomeration economies, which render capital regions more sensitive to severe shocks such as the recent crisis (Dijkstra et al. 2015). Lastly, patent stock per capita $\left(P A T p c_{i, 2006}\right)$ is positive but not significant. This result underlines that is not the technological capital per se to matter, rather how it is adaptive and resistant to recurrent crises. ${ }^{12}$

It is plausible, looking at our results, to assume that our results depend upon the initial economic conditions of the regions. In particular, we can expect that the role of technological resistance and human capital in attenuating the economic effect of the crisis could be larger in healthier regions that have more resources and a more diversified economic and technological structure. So, we perform additional estimates distinguishing between regions according to the pre-crisis level of the unemployment rates. We use the median value of the unemployment rate in 2007 as a cut off value. Table 5 reports the results.

Models $4 a-7 a(4 b-7 b)$ refer to those regions with a level of unemployment rate in 2007 above (below) the median value. Models $6 \mathrm{a}, 6 \mathrm{~b}, 7 \mathrm{a}$ and $7 \mathrm{~b}$ include the interaction between technological resistance and human capital. Models 5a, 5b, 7a and 7b include country dummies (Germany is used as reference category; see Table 7 in the Appendix $B$ for the values of the estimated country fixed effects).

We highlight three main findings. First of all, the positive effect of technological resistance on economic resistance are confirmed. Considering the sample of regions with a lower unemployment in 2007, the positive and significant effect of technological resistance is larger relative to the full sample (Model 5b). Conversely, for regions with a higher level of unemployment in 2007, the positive effect of technological resistance (see Models 4a and 6a) becomes insignificant after controlling for country dummies (see Models 5a and 7a). These results suggest that, for disadvantaged regions, country characteristics are more important than their technological resistance.

Second, the interaction term between human capital and technological resistance is positive and statistically different from zero only in those regions with a lower unemployment rate in 2007 (see Models $6 \mathrm{~b}$ and $7 \mathrm{~b}$ ). ${ }^{13}$ So, our results indicate that

\footnotetext{
${ }_{12}$ Several additional estimates are performed controlling for (1) the distribution of extreme-values of technological and unemployment resistance, (2) the potential biases for the inclusion of regions with a positive value for the dependent variable (i.e. the invulnerable regions), and for the exclusion of the regions with no technological recessions before 2006, (3) the potential biases in the measurement of the regions' technological resistance capacity, (4) the regions' pre-crisis unemployment trend, (5) uncertainty about the exact starting date of the regions' crisis periods (Sensier et al. 2016). Overall, these robustness checks validate our main results (for further details, see the Appendix A).

${ }^{13}$ Also in this case (see footnote 11) we have estimated the effect of technological resistance on "GDP per capita resistance". We rank regions according to the pre-crisis level of the GDP per capita. We use the median value of the GDP per capita in 2007 as a cut off value. Our results are in line with ones in Table 5 . Technological resistance affects the post-crisis regional performance in terms of GDP per capita only for the group of richer regions. Contrary to what we find in Table 5, we also find a positive effect of human capital. Results are available upon request. These results taken together raise the interesting question on why human capital has a stronger effect on GDP per capita resistance while its positive effect on unemployment resistance takes place only if coupled with a high level of technological resistance. This result is in line with Crescenzi et al. 2016 and suggests that, after a crisis, human capital, while being an important driver of GDP per capita growth, does not inhibit job losses in many segments of the labor market.
} 
only the more solid regions are able to exploit the joint effect of high levels of human capital and the ability to react in terms of technological capacity. Finally, there is a significant negative effect of human capital (see Model $4 \mathrm{~b}$ and $5 \mathrm{~b}$ ), suggesting that higher human capital endowments might results in higher unemployment rates if the human capital is not supported by a technological capital that is resistant to crisis., ${ }^{1415}$

\subsection{Gender, age and unemployment duration}

Finally, we analyze whether the effects of technological resistance and human capital on unemployment resistance differ by gender, age (i.e. young: age 15-24 vs. elders: age > 24 ) and unemployment duration (i.e. long-term unemployed: unemployment condition $>12$ months). Table 6 reports the results (Models 8a-12a), including the interaction term between technological resistance and human capital (Models 8b-12b). All regressions in Table 6 include the full set of control variables and country dummies. Sample size differences between the different models are due to data constraints, i.e. the lack of information on the unemployment rates of the considered unemployment category. ${ }^{16}$

For what concerns unemployment rates by gender, Models $8 \mathrm{a}, 8 \mathrm{~b}, 9 \mathrm{a}$ and $9 \mathrm{~b}$ in Table 6 show that technological resistance and its interaction with human capital have a significant positive impact on unemployment resistance only for males (and not for females). ${ }^{17}$ For what concerns age, technological resistance and its interaction with human capital are both positive and significant for young people (see Models 10a and 10b), while only the interaction term exerts a positive significant effect for the elders (see Model 11a and 11b). Finally, we observe a statistically significant effect of both technological resistance and of the interaction term on the unemployment resistance of long-term unemployed (see Models 12a and 12b). Taken together, our results suggest that technological resistance and its interaction with human capital have a positive

\footnotetext{
${ }^{14}$ In some regions, skilled workers could crowd out unskilled workers (Ramos et al. 2009; Cadil et al. 2014). After an adverse economic shock, regions with a high level of human capital but economically weak could suffer from a displacement of unskilled jobs by skilled workers. Possibly this could increase, especially for the less educated group of population, the unemployment level. However, regions with a technological resistant capital are less affected by these effects because high-skilled people are more likely to keep their jobs, and, at the same time, there is less pressure, in terms of stagnating labor demand, for the low-skilled workers.

${ }^{15}$ With regard to the other control variables, we find that technological specialization has a positive effect in poorer regions (see Model 7a) and a negative effect for richer regions (see model 7b). For the richest regions, the results suggest that diversified regions are less affected by economic shocks since technological diversification reduces the regions' exposure and sensitivity to different types of shocks (Frenken et al. 2007). Moreover, we find, as expected, a negative effect of the construction industry, but only for poorer regions (see Model 7a), and a positive effect of the agriculture industry, but only for the richer regions (see Model 7b). For the latter, the existing literature has underlined the role of agriculture as a buffer against unemployment for the most vulnerable groups in society (see e.g. Perugini and Signorelli 2010). The initial economic condition (GDP per capita level) affects regional performance only within the group of richer regions (see Model 7b). As expected, the country dummies are negative and statistically significant in most of the cases for both samples (see Table 7 in the Appendix B).

${ }^{16}$ We have also performed an additional set of robustness checks to compare the effects of technological resistance and human capital on unemployment performance across the different unemployment categories using the same number of observations. So, we re-estimate the models in Table 6 for the subsample of 196 regions for which we have unemployment data for all the categories. In general, the estimates (see Table 8 in the Appendix C) are similar to those in Table 6 (except for the significance level which is lower in some cases) confirming that technological resistance has a significant role above all for young and male people.

${ }^{17}$ We also used only the human capital of males (females) in Models 8a and 8b (Models 9a and 9b). The estimates results (available from the authors upon request) are very similar.
} 


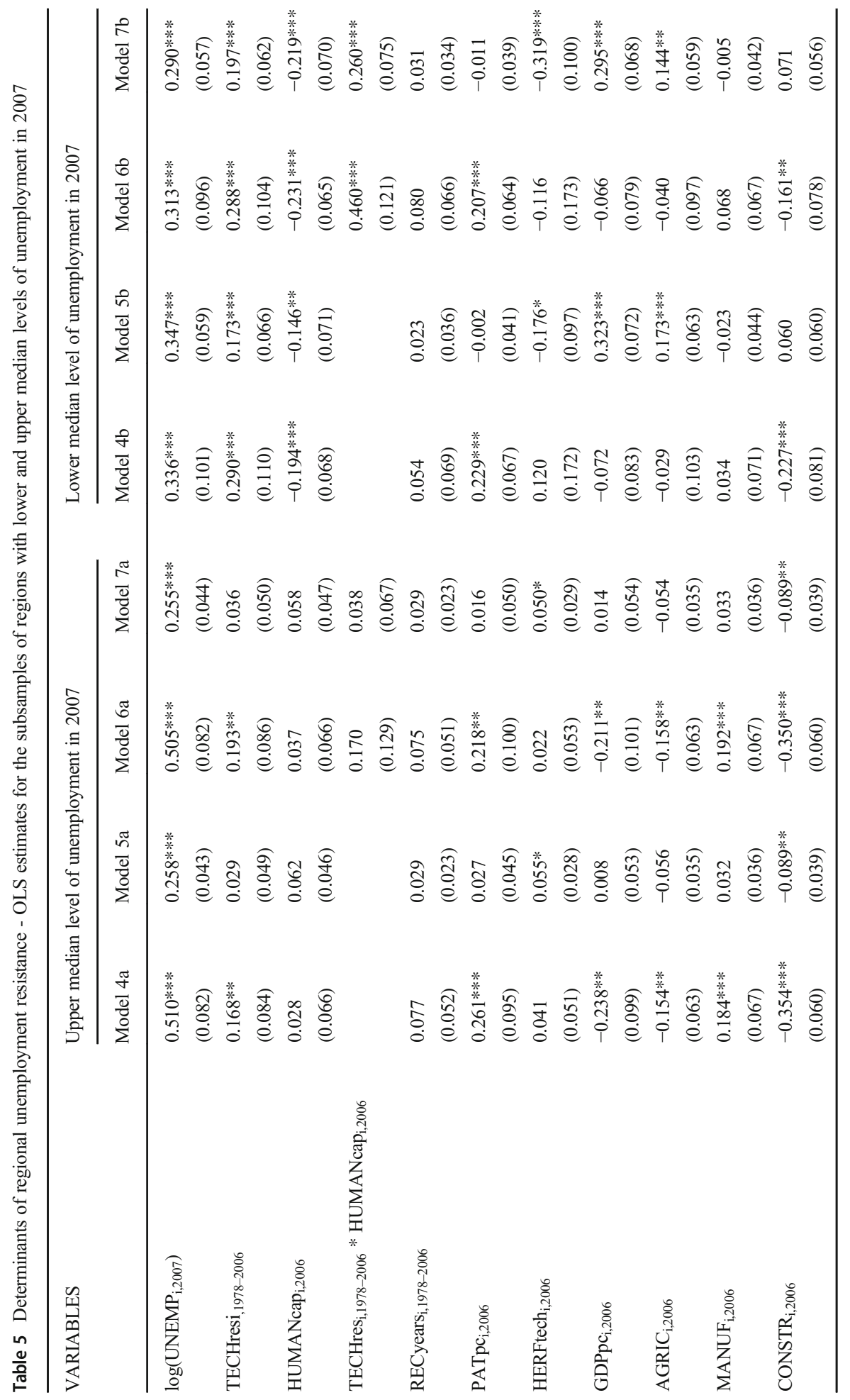




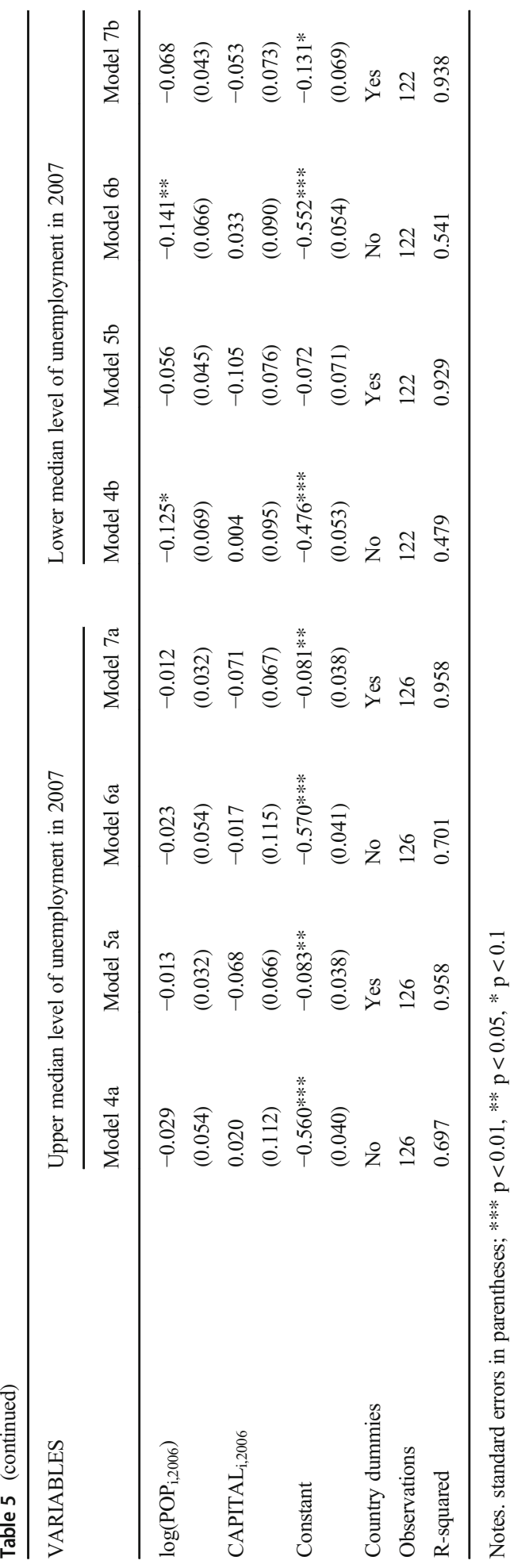


effect, especially upon the unemployment resistance of young males and on long run unemployed.

Interestingly, young and male people are two categories severely hit by the recent economic crisis (Verick 2009). However, we underline that technological resistance and its interaction with human capital seem to be less effective in reducing the unemployment growth of female and adult workers when a region is hit by an economic downturn. If this effect is particularly strong and persistent, this finding suggests that the crisis can potentially widen the gap between advantaged and disadvantaged groups in the labor market.

\section{Conclusions and discussion}

This study investigates the determinants of regional resilience in the EU to understand the role of technological resilience and human capital during the 2008 crisis. Our analysis allows us to grasp a number of important issues that improve our understanding of regional resilience. First of all, we tackle directly the relationship between technological resilience and economic resilience. To measure technological resilience, we adopt a measure based on Balland et al. (2015). We identify for each European region their technological crises, defined as a decline in the patenting activity. We exploit the distance between the peak and the trough in the time series to study the relative capacity of a region to maintain its technological activity over time, in particular when the region faces adverse shocks. We look at all technological crises in the regions since 1978 with the underlining assumption that the past capacity of a region to absorb shocks and remain innovative and competitive is a way to capture the technological resistance of a region. For economic resilience we select the dimension of unemployment resistance. We analyze the impact of the 2008 crisis in European regions and we show that technological resistance is a good predictor of unemployment resistance. There is a strict link between the past ability of regions to sustain the production of knowledge and the ability of a regional economic system to resist in term of unemployment rates to the 2008 crisis. This occurs for many European regions and, in particular, for those that were economically more solid before 2008 .

A second important issue is human capital. We show that there is a process of reciprocal reinforcement between the technological capacity of regions to absorb shocks and the level of human capital at the regional level. On the one hand, technological resistance is more effective in regions with high levels of human capital. On the other hand, human capital alone, after a crisis, is not enough to sustain the economic regional system if it's not coupled with a more general ability of the region to re-orient innovative resources and technologies to shape a new growth path. This ability is to a great extent a legacy of the past technological history.

Third, we observe different levels of unemployment resistance of the different components of the labor force. We show that the effectiveness of technological resistance and human capital to reduce the unemployment impact of the 2008 crisis regards, in particular, male and young workers and long-term unemployed. As a consequence, at a regional level technological resistance and the level of human capital are less effective in protecting female and elderly after an economic crisis. 
Finally, regions are deeply embedded in the national institutional set of norms, regulations and policies. In line with other studies (Crescenzi et al. 2016; Groot et al. 2011), our findings show that, for regional economic resilience, country effects are extremely relevant. We believe that the complex interaction between the regional development paths and the institutional and policy variables at the country level are a key aspect that should be taken up for further research by the buoyant stream of literature on regional resilience.

This paper has a number of important limitations that represent questions for further research. In our study we focus on unemployment resistance and show its relationship with technological resistance. In the literature other dimensions of resistance have been discussed (Martin 2012), so the analysis of the impact of technological resistance and human capital can be expanded to other economic dimensions (e.g. Crescenzi et al. 2016). In addition, the specific institutional and economic mechanisms that drive the results of our paper remain to a large extent a black box. The long term reorientation and renewal of regions is of particular interest, since some evidence shows how new industries branch out from existing ones (Boschma 2015). However, less is known on how these dynamics unfold during crisis events and what specific determinants play a role. Third, a more nuanced understanding of national institutions is needed. Our findings show that regional dynamics are importantly shaped by national factors. These factors can possibly be ascribed to national institutions and policies. It would enrich the analysis to incorporate in the framework additional institutional variables and spell out more precisely their role.

As far as policy implications are concerned, our analysis shows that investment in innovation, which is usually justified for its role in boosting the competitiveness of regional economies, plays an important role in times of crisis. This implies that innovation investment could be regarded as a counter-cyclical factor in the context of macro-stabilization policies. Our paper suggests, however, that it's not just R\&D expenditures or human capital alone that makes regions resilient. We suggest that what matters is the ability of a regional innovation system to adapt to changing conditions and remain innovative reorienting skills and resources. This points at innovation policies that are specific for each region and aimed at identifying and solving regionspecific bottlenecks. This raises the important issue of the integration between regionspecific innovation policies and national macroeconomic policies.

A second policy implication of our analysis concerns, therefore, the level at which "resilience" operates. Although our study has a regional focus, our findings show that the macro national setting explains large part of the regional variation in unemployment resistance. So regional policies cannot be effective if not coordinated with national ones and any regional effort to cope with the crisis could prove to be ineffective if in contrast with national policies. We find also that, for disadvantaged regions, country characteristics are more important than technological resistance. In addition, only the more solid regions are able to exploit the joint effect of high levels of human capital and the ability to react in terms of technological capacity. As a result, our paper indicates that innovation policies, aimed at reinforcing regional innovation systems and their technological resistance, are probably more effective in economically advanced regions.

A final policy implication is related to the asymmetric impact of technological resistance and its interaction with human capital in the labor market. We find that, after a crisis, technological resistance and human capital are less effective in reducing 


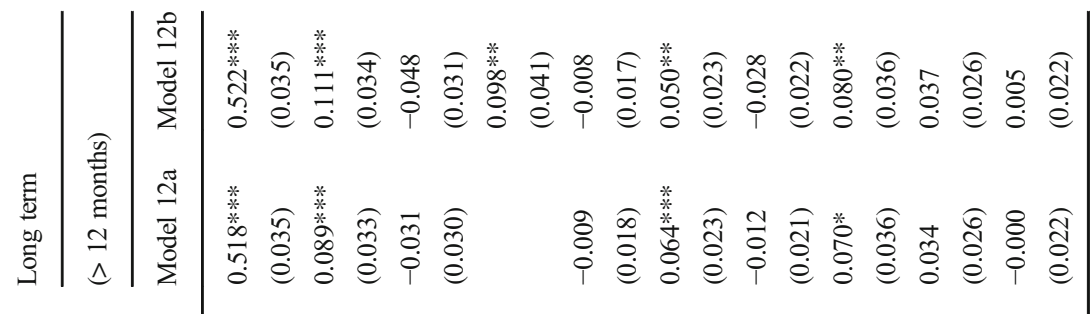

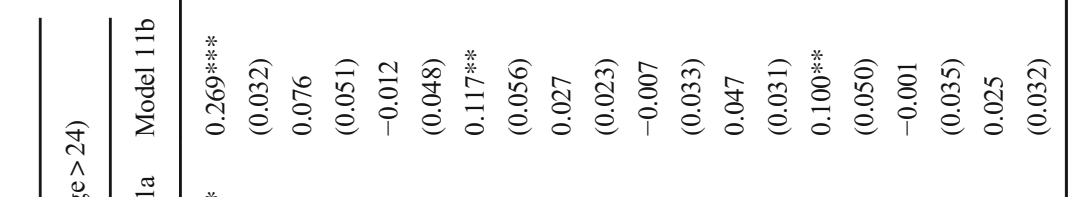

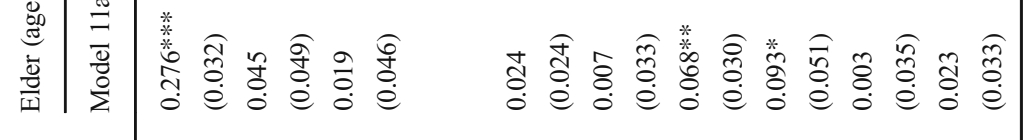

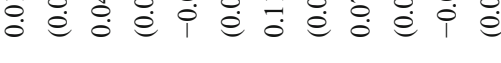

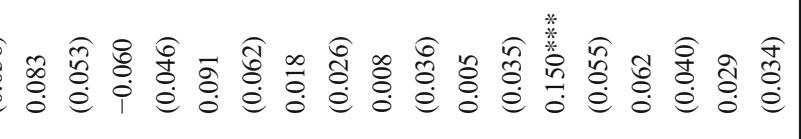

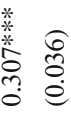

药

ố

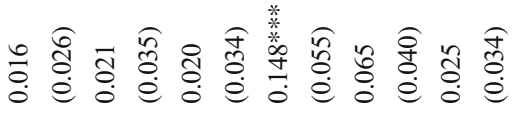
$\mid \begin{aligned} & \infty \\ & \frac{0}{8} \\ & \frac{0}{2} \\ & \frac{\pi}{0} \\ & \frac{\pi}{8} \\ & \sum\end{aligned}$

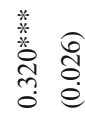

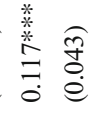
ते

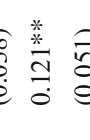

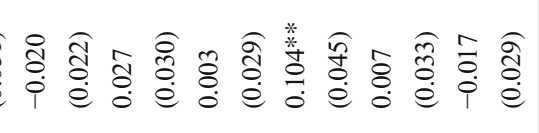
\begin{tabular}{|l}
$\overrightarrow{0}$ \\
$\overline{0}$ \\
$\overline{0}$
\end{tabular}

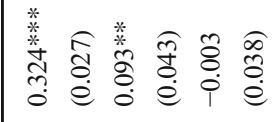

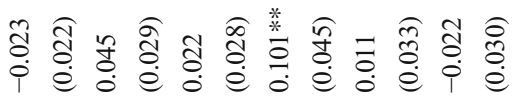

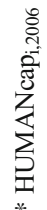

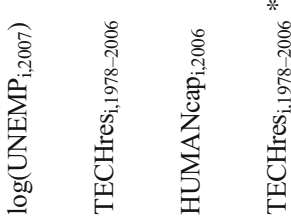

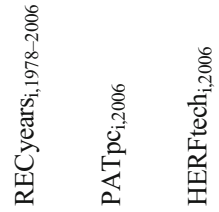

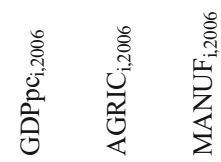




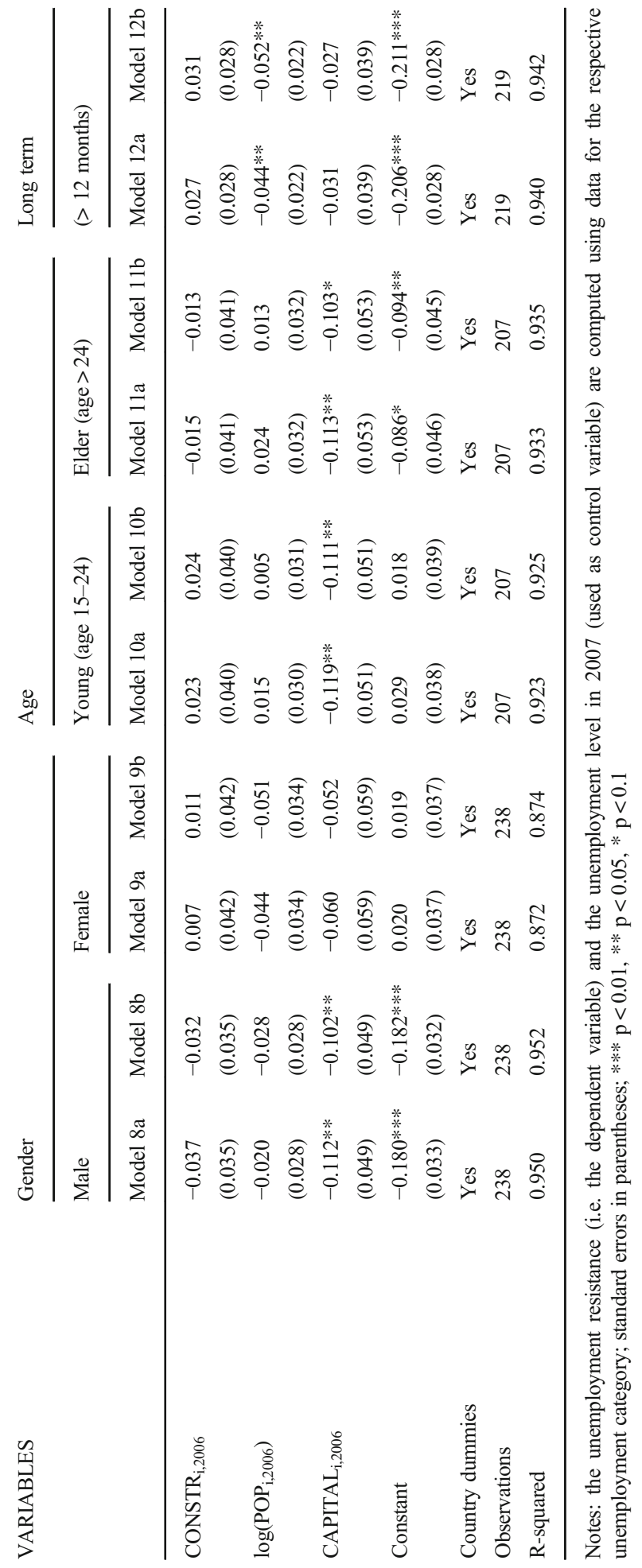


the unemployment growth of female and adult workers. It is very important that innovation policies take into account the issue of aging, skill acquisition and learning. In addition, a potential gender bias exists if innovation policies favor industries and occupations with a relatively higher presence of men.

Funding informaion Open Access funding provided by Università Politecnica delle Marche within the CRUI-CARE Agreement. Financial support from the University of Torino "Progetti di Ateneo 2017" and the Collegio Carlo Alberto project "RENIR", Compagnia di San Paolo is gratefully acknowledged by Riccardo Cappelli.

\section{Compliance with ethical standards}

Conflict of interests The authors declare that they have no conflict of interest.

\section{Appendix: Robustness checks}

Various checks are conducted to validate the robustness of the main results of this paper. The results of these robustness checks, not reported here, are available upon request from the authors.

To exclude the possibility that the relationship between technological and unemployment resistance is driven by extreme values in both variables, a new set of estimates are performed. First, estimates are performed excluding the first and last percentile of the dependent variable. Then, additional estimates are performed excluding the first and last percentile of the mean peak-trough ratio. The obtained results are very similar to those discussed above. Moreover, to exclude the possibility that the results are driven by regions with a positive value for the dependent variable, new estimates are performed excluding these regions. Again, the results are similar to the original estimates.

Ten regions were excluded from the original sample of regions because no technological recession phases were observed for these regions. As a robustness check, we perform new estimates including this group of ten regions, assigning a zero value to their mean peak-rough ratio and using a control dummy common to this group. The estimates results are very similar.

To measure the regions' technological resistance the authors of this paper rely on the mean value of the peak-trough ratios observed for the period 19782006. To control for potential biases due to possible errors in the measurement of the regions' technological resistance capacity, new estimates are performed using alternative measures, i.e. the minimum value of the peak-trough ratios, the maximum value of the peak-trough ratios and the mean value of the peaktrough ratios calculated, excluding the earliest technological recession phase. These new variables are highly correlated with the original variable. The estimates results are very similar to those reported in the main text.

To control for a possible trend in the unemployment rate of a region, a set of estimates are performed including the average annual variation of the unemployment rates during the period 1999-2007. These OLS regressions consider a sub-sample of 214 regions because for 34 regions there are missing data on the unemployment rates for the period 1999-2006. Again, the results are similar to the original estimates. 
Finally, we control for potential biases due to potential measurement errors in dating the starting period of the crisis. Using data on employment for European regions, a recent paper of Sensier et al. (2016) shows that the starting year of the crisis period might vary by region. The authors find that the crisis reveals its firsts effects in 2006 and the peak in the number of regions in recession is reached in 2009. In line with Sensier et al. (2006), we construct an additional measure of unemployment resistance by allowing at the crisis period to start in any year of the period 2006-2009 and to vary among regions. In particular, for each region, we identify the year $t$ with the minimum unemployment rate during period 2006-2009 and consider the subsequent year $t+1$ as the starting year of the crisis period. Then, we calculate the unemployment resistance as the difference between the level of unemployment rate before crisis (year $t$ ) and the peak level of unemployment rate of the crisis period (from $t+1$ to the last period covered by our data, i.e. 2016). This alternative measure of unemployment resistance is used in additional estimates where all the independent variables are measured in the year 2004. The results of this estimates are very similar to those reported in the main text of the paper.

\section{Appendix Complete table of OLS estimates for Models $3 \mathrm{~b}, 7 \mathrm{a}$ and $7 \mathrm{~b}$}

Table 7 OLS estimates results for the total sample (Model 3b) and for the two subsamples of regions with lower (Model 7b) and upper median (Model 7a) levels of unemployment in 2007- Country dummy coefficient values are included

\begin{tabular}{|c|c|c|c|}
\hline VARIABLES & $\begin{array}{l}\text { Total } \\
\text { sample }\end{array}$ & $\begin{array}{l}\text { Upper median level } \\
\text { of unemployment in } 2007\end{array}$ & $\begin{array}{l}\text { Lower median level } \\
\text { of unemployment in } 2007\end{array}$ \\
\hline & Model 3b & Model 7a & Model 7b \\
\hline \multirow[t]{2}{*}{$\log \left(\right.$ UNEMP $\left._{i, 2007}\right)$} & $0.258 * * *$ & $0.255^{* * *}$ & $0.290 * * *$ \\
\hline & $(0.026)$ & $(0.044)$ & $(0.057)$ \\
\hline \multirow[t]{2}{*}{ TECHres $_{i, 1978-2006}$} & $0.132 * * *$ & 0.036 & $0.197 * * *$ \\
\hline & $(0.040)$ & $(0.050)$ & $(0.062)$ \\
\hline \multirow[t]{2}{*}{ HUMANcap $_{i, 2006}$} & -0.050 & 0.058 & $-0.219 * * *$ \\
\hline & $(0.037)$ & $(0.047)$ & $(0.070)$ \\
\hline \multirow[t]{2}{*}{ TECHres $_{i, 1978-2006} *$ HUMANcap $_{\mathrm{i}, 2006}$} & $0.158 * * *$ & 0.038 & $0.260 * * *$ \\
\hline & $(0.048)$ & $(0.067)$ & $(0.075)$ \\
\hline \multirow[t]{2}{*}{ RECyears $_{i, 1978-2006}$} & 0.023 & 0.029 & 0.031 \\
\hline & $(0.021)$ & $(0.023)$ & $(0.034)$ \\
\hline \multirow[t]{2}{*}{ PATpc $_{i, 2006}$} & -0.014 & 0.016 & -0.011 \\
\hline & $(0.029)$ & $(0.050)$ & $(0.039)$ \\
\hline \multirow[t]{2}{*}{ HERFtech $_{\mathrm{i}, 2006}$} & -0.010 & $0.050^{*}$ & $-0.319 * * *$ \\
\hline & $(0.028)$ & $(0.029)$ & $(0.100)$ \\
\hline \multirow[t]{2}{*}{$\mathrm{GDPpc}_{\mathrm{i}, 2006}$} & $0.128 * * *$ & 0.014 & $0.295 * * *$ \\
\hline & $(0.042)$ & $(0.054)$ & $(0.068)$ \\
\hline \multirow[t]{2}{*}{$\mathrm{AGRIC}_{\mathrm{i}, 2006}$} & 0.026 & -0.054 & $0.144 * *$ \\
\hline & $(0.032)$ & $(0.035)$ & $(0.059)$ \\
\hline
\end{tabular}


Table 7 (continued)

\begin{tabular}{|c|c|c|c|}
\hline VARIABLES & $\begin{array}{l}\text { Total } \\
\text { sample }\end{array}$ & $\begin{array}{l}\text { Upper median level } \\
\text { of unemployment in } 2007\end{array}$ & $\begin{array}{l}\text { Lower median level } \\
\text { of unemployment in } 2007\end{array}$ \\
\hline MANUF $_{\mathrm{i}, 2006}$ & $\begin{array}{l}0.016 \\
(0.027)\end{array}$ & $\begin{array}{l}0.033 \\
(0.036)\end{array}$ & $\begin{array}{l}-0.005 \\
(0.042)\end{array}$ \\
\hline CONSTR $_{i, 2006}$ & $\begin{array}{l}-0.013 \\
(0.032)\end{array}$ & $\begin{array}{l}-0.089 * * \\
(0.039)\end{array}$ & $\begin{array}{l}0.071 \\
(0.056)\end{array}$ \\
\hline $\log \left(\mathrm{POP}_{\mathrm{i}, 2006}\right)$ & $\begin{array}{l}-0.018 \\
(0.026)\end{array}$ & $\begin{array}{l}-0.012 \\
(0.032)\end{array}$ & $\begin{array}{l}-0.068 \\
(0.043)\end{array}$ \\
\hline CAPITAL $_{\mathrm{i}, 2006}$ & $\begin{array}{l}-0.095 * * \\
(0.047)\end{array}$ & $\begin{array}{l}-0.071 \\
(0.067)\end{array}$ & $\begin{array}{l}-0.053 \\
(0.073)\end{array}$ \\
\hline AUSTRIA & $\begin{array}{l}-0.129 * * \\
(0.052)\end{array}$ & $\begin{array}{l}-0.224 * \\
(0.113)\end{array}$ & $\begin{array}{l}-0.239 * * * \\
(0.069)\end{array}$ \\
\hline BELGIUM & $\begin{array}{l}-0.220 * * * \\
(0.047)\end{array}$ & $\begin{array}{l}-0.313^{* * *} \\
(0.058)\end{array}$ & $\begin{array}{l}-0.088 \\
(0.081)\end{array}$ \\
\hline BULGARIA & $\begin{array}{l}-0.433 * * * \\
(0.088)\end{array}$ & $\begin{array}{l}-0.571 * * * \\
(0.101)\end{array}$ & $\begin{array}{l}-0.205 \\
(0.158)\end{array}$ \\
\hline CYPRUS & $\begin{array}{l}-0.940 * * * \\
(0.135)\end{array}$ & - & $\begin{array}{l}-0.823^{* * *} \\
(0.162)\end{array}$ \\
\hline CZECH REPUBLIC & $\begin{array}{l}-0.236^{* * *} \\
(0.065)\end{array}$ & $\begin{array}{l}-0.175^{*} \\
(0.092)\end{array}$ & $\begin{array}{l}-0.258^{* * *} \\
(0.095)\end{array}$ \\
\hline DENMARK & $\begin{array}{l}-0.559 * * * \\
(0.067)\end{array}$ & - & $\begin{array}{l}-0.544 * * * \\
(0.082)\end{array}$ \\
\hline ESTONIA & $\begin{array}{l}-1.001 * * * \\
(0.139)\end{array}$ & - & $\begin{array}{l}-0.860 * * * \\
(0.176)\end{array}$ \\
\hline GREECE & $\begin{array}{l}-1.121^{* * *} \\
(0.059)\end{array}$ & $\begin{array}{l}-1.051^{* * *} \\
(0.065)\end{array}$ & $\begin{array}{l}-1.402^{* * *} \\
(0.140)\end{array}$ \\
\hline SPAIN & $\begin{array}{l}-1.047 * * * \\
(0.062)\end{array}$ & $\begin{array}{l}-1.016^{* * *} \\
(0.073)\end{array}$ & $\begin{array}{l}-0.907 * * * \\
(0.126)\end{array}$ \\
\hline FINLAND & $\begin{array}{l}-0.341 * * * \\
(0.074)\end{array}$ & $\begin{array}{l}-0.280^{* * * *} \\
(0.078)\end{array}$ & $\begin{array}{l}-0.382 * * * \\
(0.140)\end{array}$ \\
\hline FRANCE & $\begin{array}{l}-0.403 * * * \\
(0.037)\end{array}$ & $\begin{array}{l}-0.325^{* * *} \\
(0.040)\end{array}$ & $\begin{array}{l}-0.506^{* * *} \\
(0.079)\end{array}$ \\
\hline HUNGARY & $\begin{array}{l}-0.368^{* * *} \\
(0.070)\end{array}$ & $\begin{array}{l}-0.329^{* * *} \\
(0.081)\end{array}$ & $\begin{array}{l}-0.355^{* * *} \\
(0.121)\end{array}$ \\
\hline IRELAND & $\begin{array}{l}-1.045^{* * *} \\
(0.102)\end{array}$ & - & $\begin{array}{l}-1.201 \text { *** } \\
(0.131)\end{array}$ \\
\hline ITALY & $\begin{array}{l}-0.703 * * * \\
(0.049)\end{array}$ & $\begin{array}{l}-0.578^{* * *} \\
(0.066)\end{array}$ & $\begin{array}{l}-0.812^{* * *} \\
(0.083)\end{array}$ \\
\hline LITHUANIA & $\begin{array}{l}-0.996 * * * \\
(0.142)\end{array}$ & - & $\begin{array}{l}-0.836^{* * *} \\
(0.178)\end{array}$ \\
\hline LUXEMBOURG & $\begin{array}{l}-0.488^{* * *} \\
(0.142)\end{array}$ & - & $\begin{array}{l}-0.900 \text { *** } \\
(0.176)\end{array}$ \\
\hline LATVIA & $-0.813 * * *$ & - & $-0.672 * * *$ \\
\hline
\end{tabular}


Table 7 (continued)

\begin{tabular}{|c|c|c|c|}
\hline VARIABLES & $\begin{array}{l}\text { Total } \\
\text { sample }\end{array}$ & $\begin{array}{l}\text { Upper median level } \\
\text { of unemployment in } 2007\end{array}$ & $\begin{array}{l}\text { Lower median level } \\
\text { of unemployment in } 2007\end{array}$ \\
\hline & $(0.142)$ & & $(0.178)$ \\
\hline \multirow[t]{2}{*}{ MALTA } & 0.086 & 0.049 & - \\
\hline & $(0.141)$ & $(0.148)$ & \\
\hline \multirow[t]{2}{*}{ NETHERLANDS } & $-0.682 * * *$ & - & $-0.691 * * *$ \\
\hline & $(0.052)$ & & $(0.075)$ \\
\hline \multirow[t]{2}{*}{ POLAND } & -0.076 & -0.123 & - \\
\hline & $(0.066)$ & $(0.076)$ & \\
\hline \multirow[t]{2}{*}{ PORTUGAL } & $-0.756^{* * *}$ & $-0.684 * * *$ & $-0.753 * * *$ \\
\hline & $(0.075)$ & $(0.086)$ & $(0.163)$ \\
\hline \multirow[t]{2}{*}{ ROMANIA } & $-0.181 *$ & $-0.217 *$ & 0.088 \\
\hline & $(0.093)$ & $(0.118)$ & $(0.158)$ \\
\hline \multirow[t]{2}{*}{ SWEDEN } & $-0.388 * * *$ & $-0.391 * * *$ & $-0.370 * * *$ \\
\hline & $(0.048)$ & $(0.056)$ & $(0.081)$ \\
\hline \multirow[t]{2}{*}{ SLOVAKIA } & $-0.254 * * *$ & $-0.266^{* * *}$ & -0.208 \\
\hline & $(0.081)$ & $(0.100)$ & $(0.139)$ \\
\hline \multirow[t]{2}{*}{ UNITED KINGDOM } & $-0.400 * * *$ & $-0.422 * * *$ & $-0.318 * * *$ \\
\hline & $(0.043)$ & $(0.071)$ & $(0.075)$ \\
\hline \multirow[t]{2}{*}{ Constant } & $-0.065^{* *}$ & $-0.081 * *$ & $-0.131 *$ \\
\hline & $(0.030)$ & $(0.038)$ & $(0.069)$ \\
\hline Observations & 248 & 126 & 122 \\
\hline R-squared & 0.934 & 0.958 & 0.938 \\
\hline
\end{tabular}

Notes. standard errors in parentheses; *** $\mathrm{p}<0.01$, ** $\mathrm{p}<0.05, * \mathrm{p}<0.1$ 


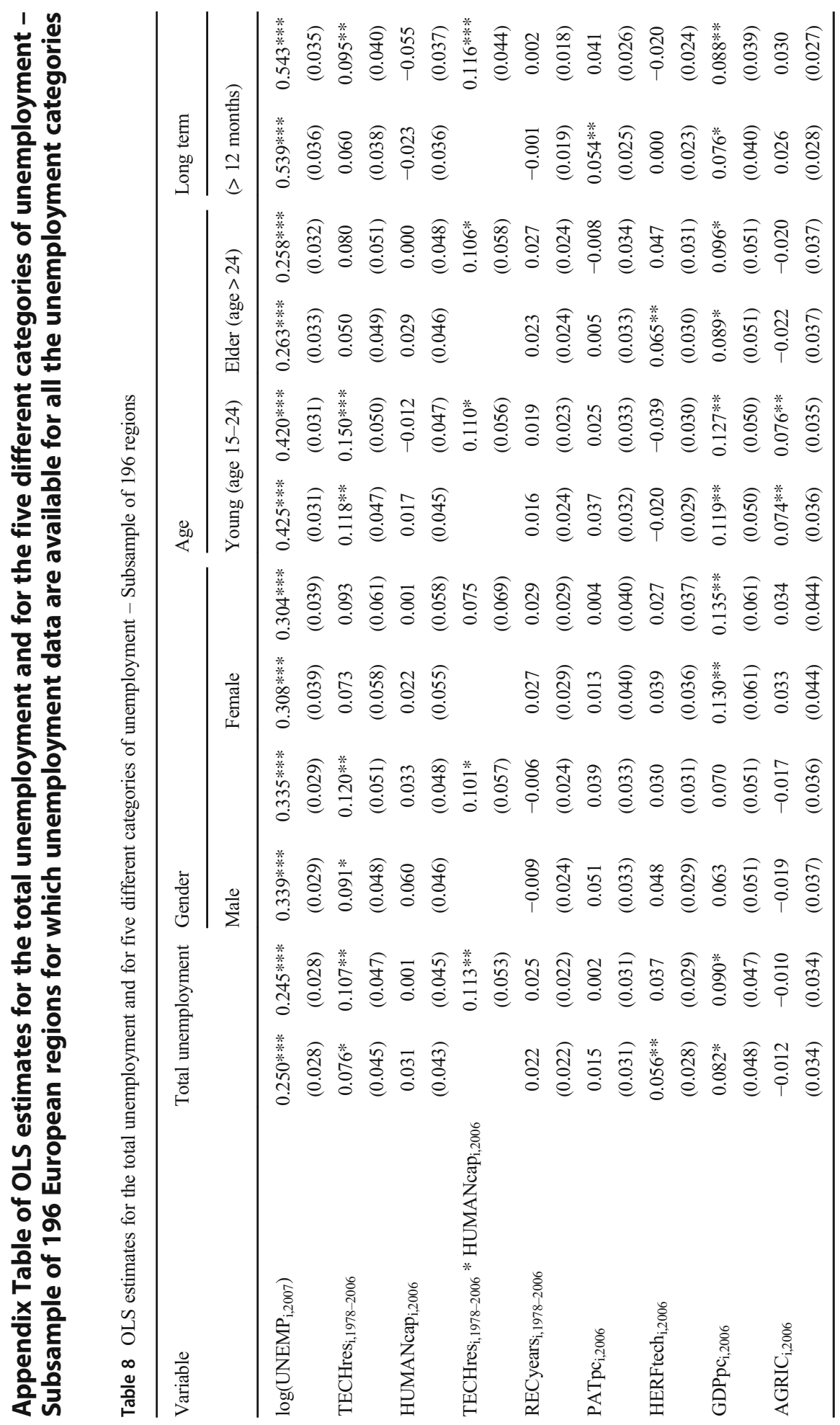




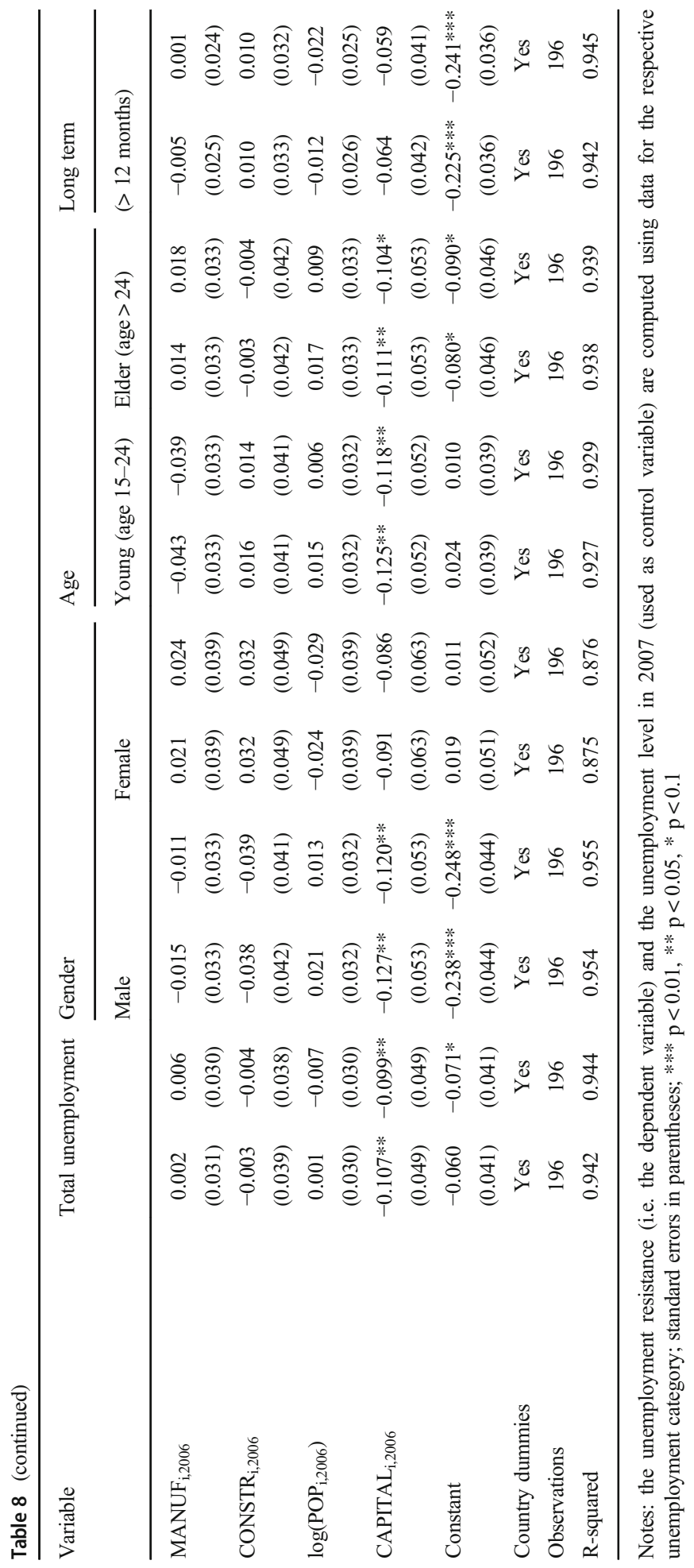


Open Access This article is licensed under a Creative Commons Attribution 4.0 International License, which permits use, sharing, adaptation, distribution and reproduction in any medium or format, as long as you give appropriate credit to the original author(s) and the source, provide a link to the Creative Commons licence, and indicate if changes were made. The images or other third party material in this article are included in the article's Creative Commons licence, unless indicated otherwise in a credit line to the material. If material is not included in the article's Creative Commons licence and your intended use is not permitted by statutory regulation or exceeds the permitted use, you will need to obtain permission directly from the copyright holder. To view a copy of this licence, visit http://creativecommons.org/licenses/by/4.0/.

\section{References}

Archibugi D, Filippetti A, Frenz M (2013) Economic crisis and innovation: is destruction prevailing over accumulation? Res Policy 42(2):303-314

Balland PA, Rigby D, Boschma R (2015) The technological resilience of US cities. Cambridge Journal of Regions, Economy and Society, Cambridge Political Economy Society 8:167-184

Blanchard OJ, Diamond P (1994) Ranking, unemployment duration, and wages. Review of Economic Studies 61(3):417-434

Boschma R (2015) Towards an evolutionary perspective on regional resilience. Reg Stud 49(5):733-751

Bristow G (2010) Resilient regions: re-'place'ing regional competitiveness. Camb J Reg Econ Soc 3(1):153-167

Bristow G, Healy A (2014) Regional resilience: an agency perspective. Reg Stud 48(5):923-935

Čadil J, Petkovová L, Blatná D (2014) Human capital, economic structure and growth. Procedia Economics and Finance 12:85-92 https://doi.org/10.1016/S2212-5671(14)00323-2

Cappelli R, Montobbio F (2016) European integration and knowledge flows across European regions. Reg Stud 50:709-727

Cappelli R, Czarnitzki D, Doherr T, Montobbio F (2019) Inventor mobility and productivity in Italian regions. Reg Stud 53(1):43-54

Crescenzi R, Luca D, Milio S (2016) The geography of the economic crisis in Europe: national macroeconomic conditions, regional structural factors and short-term economic performance. Camb J Reg Econ Soc 9(1):13-32

Coffano M, Tarasconi G (2014) Crios innos\&t database: sources, contents and access rules. CRIOS working paper N.1. http://ssrn.com/abstract=2404344

Dijkstra L, Garcilazo E, McCann P (2015) The effects of the global financial crisis on European regions and cities. J Econ Geogr 15(5):935-949

Diodato D, Weterings AB (2014) The resilience of regional labour markets to economic shocks: exploring the role of interactions among firms and workers. J Econ Geogr 15(4):723-742

Doussard M, Schrock G (2015) Uneven decline: linking historical patterns and processes of industrial restructuring to future growth trajectories. Camb J Reg Econ Soc 8(2):149-165

Eurostat (2011). Regions in the European Union, nomenclature of territorial units for statistics NUTS 2010/EU27. Eurostat methodologies and working paper http://ec.europa.eu/eurostat/documents/3859598/5916917 /KS-RA-11-011-EN.PDF.

Filippetti A, Archibugi D (2011) Innovation in times of crisis: national system of innovation, structure and demand. Res Policy 40(2):179-192

Fingleton B, Garretsen H, Martin R (2012) Recessionary shocks and regional employment: evidence on the resilience of UK regions. J Reg Sci 52(1):109-133

Frenken K, van Oort F, Verburg T (2007) Related variety, unrelated variety and regional economic growth. Reg Stud 41:685-697

Gelman A (2008) Scaling regression inputs by dividing by two standard deviations. Stat Med 27(15):2865-2873

Groot SP, Möhlmann JL, Garretsen JH, de Groot HL (2011) The crisis sensitivity of European countries and regions: stylized facts and spatial heterogeneity. Camb J Reg Econ Soc 4(3):437-456

Han Y, Goetz S.J. (2015) The economic resilience of U.S. counties during the great recession. Rev Reg Stud 45(2): 131-149

Harding D, Pagan A (2002) Dissecting the cycle: a methodological investigation. J Monet Econ 49:365-381

Hoekman J, Frenken K, van Oort F (2009) The geography of collaborative knowledge production in Europe. Ann Reg Sci 43:721-738

Huggins R, Thompson P (2015) Local entrepreneurial resilience and culture: the role of social values in fostering economic recovery. Camb J Reg Econ Soc 8(2):313-330 
International Labour Organization (ILO) (2009) Global employment trends, update may 2009. ILO publications http://www.ilo.org/empelm/pubs/WCMS_114102/lang\%2D\%2Den/index.htm.

Jaffe A, Trajtenberg M (2002) Patents. A Window on the Knowledge Economy. MIT Press, Cambridge, Citations and Innovations

Kogler DF, Rigby DL, Tucker I (2013) Mapping knowledge space and technological relatedness in U.S. cities. Eur Plan Stud 21:1374-1391

Lucchese M, Pianta M (2011) Cycles and innovation. WP-MS 2012/3, working papers series in economics, mathematics and statistics 2013/3, University of Urbino

Martin R (2012) Regional economic resilience, hysteresis and recessionary shocks. J Econ Geogr 12:1-32

Martin R, Sunley P (2015) On the notion of regional economic resilience: conceptualization and explanation. J Econ Geogr 14:1-42

Martin R, Sunley P, Tyler P (2015) Local growth evolutions: recession, resilience and recovery. Camb J Reg Econ Soc 8:141-148

McCann P, Ortega-Argilés R (2015) Smart specialization, regional growth and applications to European Union cohesion policy. Reg Stud 49(8):1291-1302

Pendall R, Foster KA, Cowell M (2010) Resilience and regions: building understanding of the metaphor. Camb J Reg Econ Soc 3:71-84

Périvier H (2014) Men and women during the economic crisis: employment trends in eight European countries. Revue de l'OFCE 133(2):41-84. https://doi.org/10.3917/reof.133.0041

Perugini C, Signorelli M (2010) Youth labour market performance in European regions. Econ Chang Restruct 43(2):151-185

Piva M, Vivarelli M (2018) Technological change and employment: is EuropeReady for the challenge? Eurasian Business Review 8:13-32

Ramos R, Suriñach J, Artís M (2009) Regional economic growth and human capital: the role of overeducation. IREA working papers 2009/04, University of Barcelona, research Institute of Applied Economics

Rocchetta S, Mina A (2019) Technological coherence and the adaptive resilience of regional economies. Reg Stud 53(10):1421-1434

Rubery J (1988) Women in recession. Routledge and Kegan Paul, London

Scarpetta S, Sonnet A, Manfredi T (2010), Rising youth unemployment during the crisis: how to prevent negative long-term consequences on a generation?. OECD social, employment and migration working papers no. 106, OECD publishing, Paris. https://doi.org/10.1787/5kmh79zb2mmv-en

Schumpeter JA (1942) Capitalism, socialism and democracy. McGraw-Hill, New York

Sensier M, Bristow G, Healy A (2016) Measuring regional economic resilience across Europe: operationalizing a complex concept. Spat Econ Anal 11(2):1-44

Sider H (1985) Unemployment duration and incidence: 1968-82. Am Econ Rev 75:461-472

Simmie J, Martin R (2010) The economic resilience of regions: towards an evolutionary approach. Camb J Reg Econ Soc 3:27-43

Verick S (2009) Who is hit hardest during a financial crisis? The vulnerability of young men and women to unemployment in an economic downturn. IZA discussion papers 4359, Institute for the Study of labor (IZA)

Publisher's note Springer Nature remains neutral with regard to jurisdictional claims in published maps and institutional affiliations.

\section{Affiliations}

\section{Riccardo Cappelli $^{1}$ • Fabio Montobbio ${ }^{2,3,4}$ - Andrea Morrison ${ }^{5,6}$}

1 Department of Economics and Social Sciences, Università Politecnica delle Marche, 60121 Ancona, Italy

2 Department of Economic Policy, Università Cattolica del Sacro Cuore, Milan, Italy

3 ICRIOS, Bocconi University, Milan, Italy

4 BRICK, Collegio Carlo Alberto, Turin, Italy

5 Department of Human Geography and Planning, Utrecht University, Princetonlaan 8a, 3584 CB Utrecht, the Netherlands

6 Department of Management and Technology, ICRIOS-Bocconi University, via Roentgen 1, 20136 Milan, Italy 